\title{
Dust Aerosols Detected Using a Ground-Based Polarization Lidar and CALIPSO over Wuhan $\left(30.5^{\circ} \mathrm{N}, 114.4^{\circ} \mathrm{E}\right)$, China
}

\author{
Yun $\mathrm{He}^{1,2,3}$ and Fan $\mathrm{Yi}^{1,2,3}$ \\ ${ }^{1}$ School of Electronic Information, Wuhan University, Wuhan 430072, China \\ ${ }^{2}$ Key Laboratory of Geospace Environment and Geodesy, Ministry of Education, Wuhan 430072, China \\ ${ }^{3}$ State Observatory for Atmospheric Remote Sensing, Wuhan 430072, China \\ Correspondence should be addressed to Fan Yi; yf@whu.edu.cn
}

Received 29 July 2014; Revised 21 October 2014; Accepted 3 November 2014

Academic Editor: Sven-Erik Gryning

Copyright (c) 2015 Y. He and F. Yi. This is an open access article distributed under the Creative Commons Attribution License, which permits unrestricted use, distribution, and reproduction in any medium, provided the original work is properly cited.

The vertical distribution, horizontal range, and optical properties of Asian dust were obtained using a ground-based depolarization lidar and Cloud-Aerosol Lidar and Infrared Pathfinder Satellite Observations (CALIPSO) over a two-year measurement period $(2010-2012)$ in Wuhan $\left(30.5^{\circ} \mathrm{N}, 114.4^{\circ} \mathrm{E}\right)$, China. The depolarization lidar registered 13 dust events, most of which occurred in the spring (5 events) and winter ( 6 events). The dust layers occurred at heights of approximately $1.4-3.5 \mathrm{~km}$. The horizontal ranges of the dust plumes were approximately $750-2400 \mathrm{~km}$, based on the CALIPSO data. The average volume depolarization ratio $(\delta)$, particle depolarization ratio $\left(\delta_{p}\right)$, extinction and optical depth (AOD) of the dust layers were $0.12,0.22,0.19 \mathrm{~km}^{-1}$, and 0.32 , respectively. The dust layers observed in the winter occurred at a lower height and had larger mean extinction and AOD, and smaller mean $\delta$ and $\delta_{p}$ than the spring dust layers. These wintertime features may result from a lower troposphere temperature inversion, the mixing of local aerosols, and hygroscopic growth under suitable relative humidity conditions. A dust event in April 2011 spanned 9 days. Compared with the observations at other sites, the dust layers over Wuhan exhibited more turbid along with suppressed nonspherical particle shape.

\section{Introduction}

Water loss and soil erosion induce dust emissions, which affect the large-scale atmospheric environment. Dust aerosols primarily originate in arid and semiarid areas. Dust particles entrained from desert surfaces by strong air convection are transported with the wind in the atmosphere [1-5].

There are three vast desert areas on Earth: the Sahara Desert, the East Asian Desert, and the Arabian Peninsula Desert. These deserts contribute $40 \%$ of the total aerosol loading in the atmosphere [6]. Specifically, Asian dust contributes $800 \mathrm{Tg}$ of dust aerosols to the atmosphere which occupies $40-80 \%$ of the total dust emission ( 1-2 Pg) [7] every year, and $30 \%$ settles back onto the desert areas of Asia, 20\% is transported on an intercontinental scale, and the remaining $50 \%$ is transported in the atmosphere over the Pacific or farther [8]. Asian dust affects areas far from the source regions via long-range transport $[9,10]$. During this transport, dust particles undergo complex physical and chemical processes and play an important role in the atmospheric radiation budget $[4,11,12]$.

Lidar, due to its high temporal and spatial resolution, is an important tool for measuring the vertical distribution and optical properties of dust, and ground-based lidar has been widely used in recent studies to observe Asian dust [13-17]. Sakai et al. [16] observed a dust event on 23 April 2001 in Tsukuba. The aerosol depolarization ratios at a height of approximately $5 \mathrm{~km}$ exceeded 0.2 , and the optical depth between heights of $4 \mathrm{~km}$ and $7 \mathrm{~km}$ was 0.18 . Kim et al. [18] observed an enhanced aerosol extinction of $\sim 0.015 \mathrm{~km}^{-1}$ at a height of $3-5 \mathrm{~km}$ in Seoul, Korea, in the spring seasons during the period 1997-2004, which indicates the effect of the dust. Since its launch in 2006, CALIPSO lidar has been widely used to obtain both local and global perspectives of dust optical properties and horizontal ranges [19-24]. Using CALIPSO data, Kim et al. [22] observed a dust plume that developed over South Korea on 29-31 May 2008, finding that a majority of the plume traveled 250-300 km across South Korea. Also 
TABLE 1: Specification of the depolarization lidar system at Wuhan University.

\begin{tabular}{lclc}
\hline & Transmitter & & Receiver \\
\hline Laser & Continuum Inlite II-20 & Telescope & 300 mm Cassegrain \\
Wavelength & $532 \mathrm{~nm}$ & Diameter & $300 \mathrm{~mm}$ \\
Energy/pulse & $25-40 \mathrm{~mJ}$ & Field of view & $1 \mathrm{mrad}$ \\
Repetition rate & $20 \mathrm{~Hz}$ & PMT & Hamamatsu 5783P \\
Beam divergence & $6 \mathrm{~ns}$ & Acquisition instrument & Licel TR40-160 \\
\hline
\end{tabular}

using CALIPSO data, Huang et al. [20] observed that dust layers over the Tibetan Plateau during the summer of 2006 appeared frequently at heights of approximately $4-7 \mathrm{~km}$ and had a mean volume depolarization ratio and color ratio of 0.21 and 0.83 , respectively. Most lidar observations have focused on northwest and north China, Japan, and Korea; however, few such studies have focused on southeast China $[23,25,26]$. Southeast China, which is not located in the path of the prevailing westerlies, may exhibit certain unique dust features after transport. Long-term joint observations using ground-based lidar and CALIPSO lidar in Wuhan provide an opportunity for studying the vertical distribution, horizontal range, and optical properties of dust in this region of China. In this paper, polarization lidar was used to identify nonspherical dust particles and measure the dust's optical properties, and the CALIPSO data were used to assess the horizontal range of the dust plume.

The paper is organized as follows. The current situation of dust research is first introduced. In Section 2, the instruments and data processing are described. In Section 3, the results of the dust observations over Wuhan are presented with two case studies and statistical analysis. In Section 4, the differences between the dust characteristics in the spring and winter over Wuhan are discussed. Special dust optical properties are also discussed by making comparisons with other sites in this section. Finally, the conclusions are provided in Section 5 .

\section{Instruments and Data}

2.1. Polarization Lidar System. Wuhan $\left(30.5^{\circ} \mathrm{N}, 114.4^{\circ} \mathrm{E}\right)$ is located in southeast China. The polarization lidar system that was used is installed at Wuhan University. The lidar system parameters are presented in Table 1. The polarization lidar transmitter used an Nd:YAG laser to produce an emission of $\sim 25-40 \mathrm{~mJ}$ per pulse at $532 \mathrm{~nm}$ with a repetition rate of $20 \mathrm{~Hz}$ and a pulse width of $6 \mathrm{~ns}$. The polarization purity of the transmitting laser was approximately $1 / 10000$. On the receiver side, the backscattered photons were collected using a $300 \mathrm{~mm}$ Cassegrain telescope that was followed by a fieldstop iris and a collimating lens. Double cubic polarizing beam splitters was employed to split the beam into two independent polarization channels in parallel and perpendicular directions relative to the outgoing laser beam. The filters for the two channels have a band width of $\sim 10.6 \mathrm{~cm}^{-1}(0.3 \mathrm{~nm}$ at $532 \mathrm{~nm})$. The two closest rotational Raman lines $\left(\mathrm{N}_{2}\right)$ are $\pm 11.9 \mathrm{~cm}^{-1}$ away from the elastic Cabannes line. Furthermore the pure rotational Raman lines are $\sim 3$ orders of magnitude weaker in intensity than the elastic Cabannes line. Thus the cross-talk of pure rotation Raman line was negligible [27]. The cross-talk between the two polarization channels is considerably suppressed by using double cubic polarizing beam splitters at each channel. The beams of the two channels were then detected using two photomultiplier tubes (PMT). The output pulses from the PMT were gathered using a signal acquisition instrument (Licel).

The spatial and temporal resolutions of the lidar system were $30 \mathrm{~m}$ and 1 minute, respectively. The lower lidar observation limit was $0.3 \mathrm{~km}$, which was determined based on the overlap of the laser and the field of view of the telescope. Our calibration for the polarization lidar was made by observing a fully depolarized light from thick-cloudcovered sky [28]. The resulting gain ratio $(k)$ between the two channels was 0.065 . The aerosol extinction was calculated using the combined parallel and perpendicular channels [29]. The volume depolarization ratio $\delta$ was calculated using the equations

$$
\delta=k \frac{I_{\perp}}{I_{\|}}
$$

where $I_{\|}$and $I_{\perp}$ are the signals from the parallel and perpendicular channels, respectively. $\delta$ is the volume depolarization ratio caused by molecules and aerosols.

The particle depolarization ratio $\delta_{p}$ was derived from the total-to-Rayleigh backscattering ratio BR and the volume depolarization ratio $\delta$ from the following equation [30]:

$$
\delta_{p}(z)=\frac{\delta(z)\left[\mathrm{BR}(z)+\mathrm{BR}(z) \delta_{m}-\delta_{m}\right]-\delta_{m}}{\operatorname{BR}(z)-1+\operatorname{BR}(z) \delta_{m}-\delta(z)},
$$

where $\delta_{m}$ is the molecular depolarization ratio for the lidar system. The value of molecular depolarization ratio measured by lidar depends on the wavelength and spectrum width of the detected light. The band widths of two filters used in our lidar system are both $0.3 \mathrm{~nm}$. On the basis of calculation by Behrendt and Nakamura [27], the molecular depolarization ratio computed for Cabannes line is slightly larger than the theoretical value of 0.00363 for linear polarized incident light and 180-degree backscattering (see Figure 4 of [27]). Noting that the cross-talk of pure rotational Raman is negligible and the molecular depolarization ratio does not change with the variation of atmospheric temperature, the value of $0.4 \%$ was used here. The value of $\mathrm{BR}$ is defined as $\operatorname{BR}(z)=1+$ $\beta_{a}(z) / \beta_{m}(z)$ [31], where $\beta_{m}$ and $\beta_{a}$ are the molecular and aerosol backscattering coefficients, respectively.

The aerosol extinction was calculated from the Mie backscattering signal using the method of Fernald [32]. 
Simultaneous measurement with lidar and sun photometer indicates that the average lidar ratio in the troposphere is $\sim 50 \mathrm{sr}$ (via comparing the aerosol optical depths derived from the lidar (at $532 \mathrm{~nm}$ ) and the sun photometer (at $500 \mathrm{~nm}$ ) [33, 34]). In practice, Murayama et al. [35] derived the extinction coefficient of aerosols by using the algorithm of Fernald [32], the lidar ratio of $50 \mathrm{sr}$ was chosen to reproduce the optical depth derived from the sun photometer. The lidar ratio of $50 \mathrm{sr}$ was also used in Asian dust observation in Taiwan [36] and Hefei, China [26]. Noh et al. [37] measured the lidar ratio of $51 \pm 6 \mathrm{sr}$ for Asian dust with a Raman lidar at Gwangju, Korea, in spring. Therefore, the assumed lidar ratio of $50 \mathrm{sr}$ is reasonable in this study. The molecular extinction was calculated using the U.S. Standard Atmosphere Model temperature and pressure data (U.S. GPO, Washington, D.C., 1976). The aerosol optical depth (AOD) and the centroid height $\left(z_{c}\right)$ of a dust layer are given by

$$
\begin{array}{r}
\mathrm{AOD}=\int_{Z_{b}}^{Z_{t}} \alpha_{a}(z) d z, \\
z_{c}=\frac{\int_{Z_{b}}^{Z_{t}} z \cdot \alpha_{a}(z) \cdot d z}{\int_{Z_{b}}^{Z_{t}} \alpha_{a}(z) \cdot d z},
\end{array}
$$

where $z_{t}$ and $z_{b}$ are the dust layer top and base heights, respectively, and $\alpha_{a}$ is the aerosol extinction coefficient.

2.2. Satellite Data. The Cloud-Aerosol Lidar with Orthogonal Polarization (CALIOP) instrument is carried on the CloudAerosol Lidar and Infrared Pathfinder Satellite Observations (CALIPSO) satellite and used to acquire vertical profiles of elastic backscatter at $532 \mathrm{~nm}$ and $1064 \mathrm{~nm}$ near nadir during both daytime and nighttime. The nearest CALIOP orbits pass over Wuhan at approximately 02:00 LST and 14:00 LST every day. Profiles of linear depolarization at $532 \mathrm{~nm}$ are provided. The ratio of $1064 \mathrm{~nm}$ backscattering to $532 \mathrm{~nm}$ backscattering, which is defined as the "color ratio," is also provided. This ratio represents the aerosol particle size. The depolarization ratio of dust is large because of its nonspherical shape, which is a good indicator for separating dust from other aerosols [38]. Liu et al. [23] derived the probability density functions of volume depolarization ratio (VDR) for four types of aerosol (desert dust, biomass burning, continental, and maritime). The maritime and continental aerosols had a VDR distribution peaking at zero. The biomass burning aerosols had a nonzero peak at $\sim 0.02$. The VDR distribution of the dust aerosols was centered at $\sim 0.17$. Based on these probability density functions, when a VDR threshold is set to 0.06 , only $\sim 1.4 \%$ of dust aerosol particles were left out and only $\sim 2.3 \%$ of non-dust aerosol particles were mistakenly classified as dust aerosol. Hence, in practical lidar data analysis (CALIPSO), the volume depolarization ratio value of 0.04 or 0.06 was employed as a threshold value to distinguish between dust and nondust aerosols by Liu et al. [39] and Huang et al. [21], respectively.

In this study, the CALIPSO level 1B data product was used to validate the performance of the polarization lidar and study the horizontal range of the dust plumes. The level $25 \mathrm{~km}$ aerosol profile data was used to exhibit the vertical feature mask and aerosol subtypes mask. In this product, bits 1-3 of the Atmospheric_Volume_Description represent the feature mask (1: clean air, 2: cloud, and 3: aerosol) and bits of 10-12 of the Atmospheric_Volume_Description represent the aerosol subtypes ( 0 : not determined, 1 : clean marine, 2 : dust, 3: polluted continental, 4: clean continental, 5: polluted dust, 6: smoke, and 7: other). The Level $2333 \mathrm{~m}$ and $5 \mathrm{~km}$ cloud layer data products were used to screen the clouds, as mentioned in Section 4.1.

Aura OMI (Ozone monitoring Instrument) AI (Aerosol Index) data were used to validate the presence of dust outbreak in source region. The AI indicates presence of ultraviolet- (UV-) absorbing aerosols in the atmosphere and is derived from a residual of the measured UV reflectance. The AI data is useful to detect dust aerosols [21, 25]. The daily averaged data with a horizontal resolution of $1^{\circ} \times 1^{\circ}$ was used in this paper.

2.3. Sun Photometer. A sun photometer (CE-318) was installed at our lidar site in 2008 and has been in continuous operation since then. The instrument measures the direct solar radiance and sky radiance in 8 wavelength bands (340, $380,440,500,670,870,940$, and $1020 \mathrm{~nm})$. The level 1.5 version data were used to provide spectral distribution of aerosol optical depth (AOD) after calibration and cloud screening. The uncertainties of optical depth were of the order of 0.02 (at $440-1020 \mathrm{~nm}$ ) and 0.04 (at 340-380 nm) at around noon [40]. The level 1.5 AOD data were used to derive the particle size distribution (PSD) using the algorithm of King et al. [41]. The equation used to retrieve PSD can be written as

$$
\tau(\lambda)=\int_{r_{\min }}^{r_{\max }} Q_{\mathrm{ext}}(r, \lambda, m) \pi r^{2} n(r) d r
$$

where $\tau(\lambda)$ is the aerosol optical depth at wavelength $\lambda ; r$ is the radius of aerosol particles; $r_{\max }$ and $r_{\min }$ are, respectively, the maximum and minimum radius confining the integration range; $m$ is the complex refractive exponent; $Q_{\text {ext }}(r, \lambda, m)$ is the extinction efficiency factor from Mie theory, which is the function of particle radius, wavelength, and complex refractive exponent; and $n(r)$ is the unknown particle size distribution. In this study, the integration range (radius) is $0.05-10 \mu \mathrm{m}$. The AODs at 6 wavelengths $(380,440,500,670$, 870 , and $1020 \mathrm{~nm}$ ) are used in the calculation.

2.4. HYSPLIT Backward Trajectory Analysis and Meteorological Data. The Hybrid Single Particle Lagrangian Integrated Trajectory (HYSPLIT) model was used to back-calculate the trajectories of the air mass based on atmospheric wind field data from the National Center for Environmental Prediction (NCEP) analyses [42]. It was thus possible to estimate an approximate source of each Asian dust plume.

A radiosonde was launched at 08:00 LST and 20:00 LST every day from a location approximately $24 \mathrm{~km}$ from the lidar site. The relatively humidity $(\mathrm{RH})$ and temperature data were used in this study. 


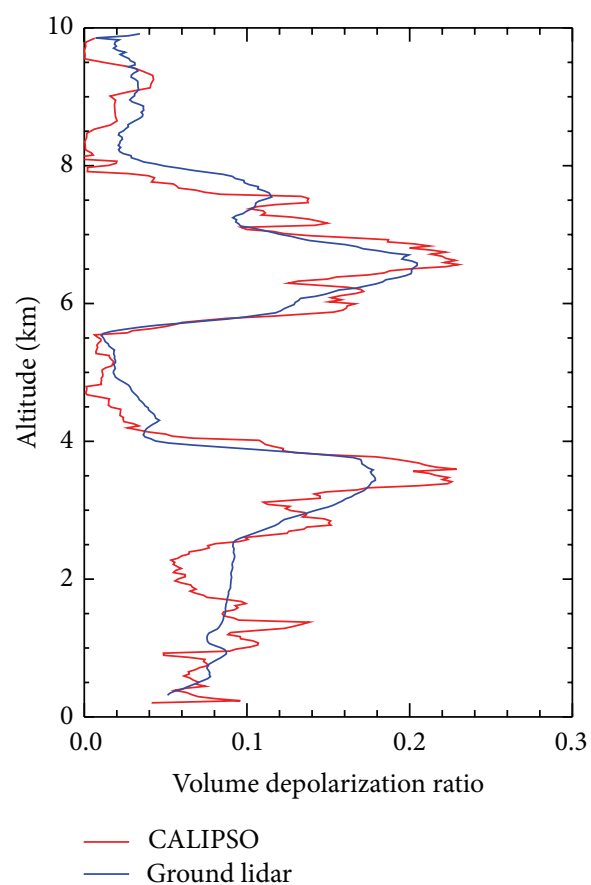

(a)

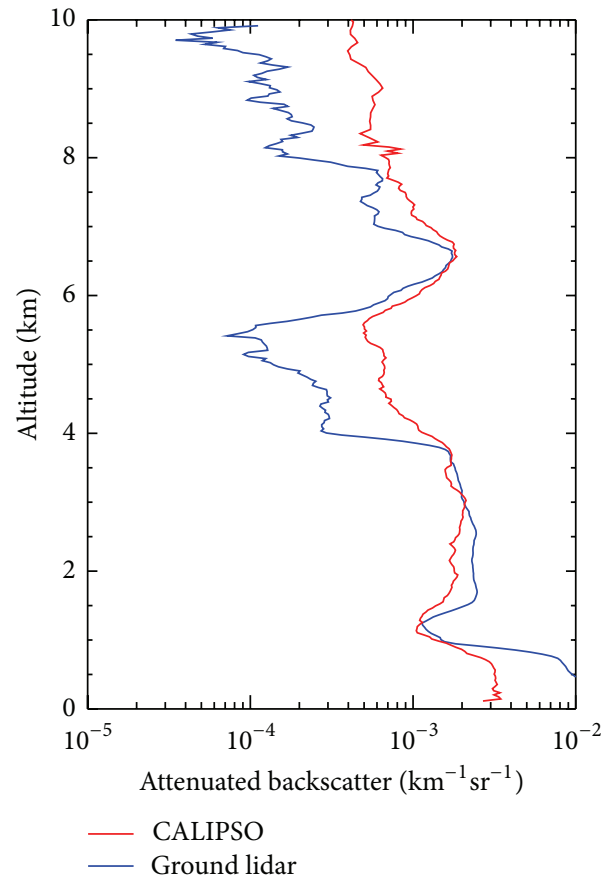

(b)

Figure 1: Comparison of the $532 \mathrm{~nm}$ (a) volume depolarization ratio profiles and (b) attenuated backscatter coefficient obtained by the depolarization lidar (blue curve) and simultaneous and nearly colocated CALIPSO measurements (red curve). The polarization lidar profile represents a $1 \mathrm{~min}$ integration from 02:24 to 02:25 LST on 23 April 2011, while the CALIPSO profile stands for a $\sim 1 \mathrm{~s}$ integration where the horizontal distances between the satellite footprint and our lidar site were less than $50 \mathrm{~km}$.

\section{Observation Results}

To validate the performance of our lidar system, a direct profile comparison of the lidar-derived optical parameters was first performed using the ground-based polarization lidar and almost simultaneous and nearly colocated CALIPSO lidar (Figure 1). The 20 profiles closest to our lidar site obtained from the CALIPSO data were averaged to compare with the $1 \mathrm{~min}$ accumulated polarization lidar data at 02:24 LST on 23 April 2011. The horizontal distances between the satellite footprint and our lidar site are less than $50 \mathrm{~km}$. Individual profiles from CALIPSO have an integration time of $\sim 1 \mathrm{~s}$ (equivalent to a horizontal distance of $\sim 6.7 \mathrm{~km}$ ). They are then smoothed with a window length of $420 \mathrm{~m}$ (14 range bins at altitudes below $8.2 \mathrm{~km}$ and 7 range bins at altitudes above $8.2 \mathrm{~km}$ ). The $1 \mathrm{~min}$ averaged profile from our ground-based lidar represents an accumulation of photon counts from 1000 laser shots. It is then smoothed with a window length of $210 \mathrm{~m}$ (7 range bins). The vertical volume depolarization ratio distributions measured using the two lidar systems quantitatively agree. The attenuated backscatter profiles exhibit a similar double-layer vertical structure of the dust layers. This comparison confirms the reliability of the vertical optical properties measured using our polarization lidar.

In this study, 13 dust events (41 observation days) observed with the ground-based polarization lidar at Wuhan were studied to reveal the vertical distribution and optical properties of dust transported over long distances from October 2010 to September 2012. Most of the dust events occurred in the spring (5 cases) and winter ( 6 cases). The remaining two events occurred in the summer and fall. Huang et al. [21] defined a dust plume as having a physical aerosol layer thickness exceeding $0.9 \mathrm{~km}$ and a volume depolarization ratio exceeding 0.06 throughout the layer. This definition was used in this study to identify dust layers. The CALIPSO level $1 \mathrm{~B}$ data during the same two years were used to estimate the horizontal range of the dust plumes. The aerosol feature mask from CALIPSO level $25 \mathrm{~km}$ aerosol profile data was shown in case studies to validate the presence of dust aerosol. Out of 13 dust events registered by ground-based lidar, 10 events were simultaneously observed with CALIPSO lidar. The remaining 3 events were missed by CALIPSO observation because of the presence of cloud. First, two case studies are discussed, representing the typical dust features in the spring and winter. Thereafter, the overall statistical characteristics of the dust plumes are discussed.

3.1. Spring Dust Case: 22-29 April 2011. The longest dust event over Wuhan was observed on 22-29 April 2011 (Figure 2). This figure presents the temporal variation of the extinction coefficient (a) and volume depolarization ratio (b) at $532 \mathrm{~nm}$. A persistent, thick dust plume of this nature has never been observed over Wuhan before. Dust layers with large $\delta$ were clearly observed at heights of approximately $0-4 \mathrm{~km}$ and $5.5-8.0 \mathrm{~km}$ beginning on the afternoon of 22 April. The 


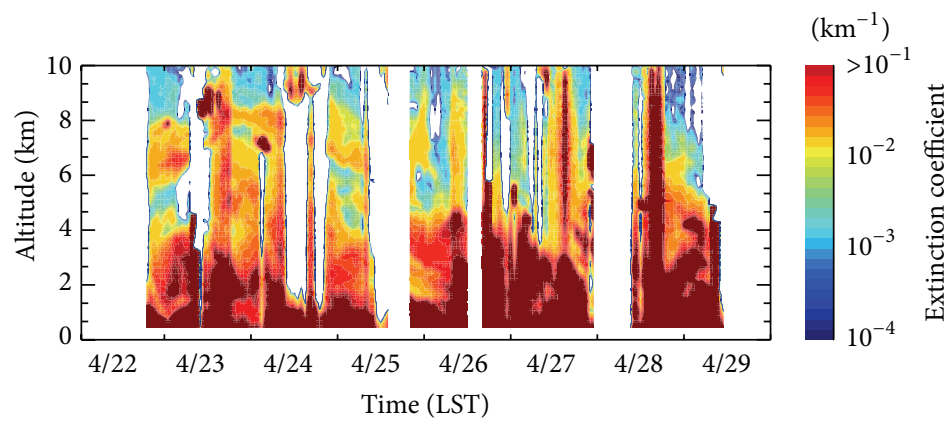

(a)

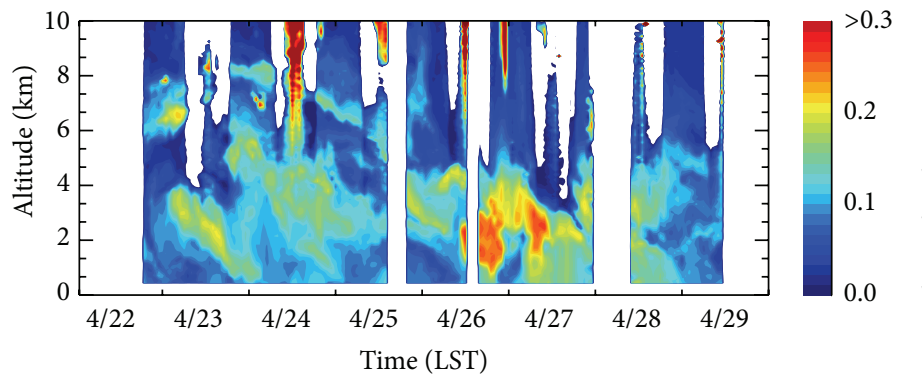

(b)

Figure 2: Temporal variation in the extinction coefficient (a) and volume depolarization ratio (b) at $532 \mathrm{~nm}$. These data were obtained using the depolarization lidar on 22-29 April 2011 over Wuhan.

upper layer steadily rose until 23 April before descending and dissipating on 25 April. The lower layer filled the lower troposphere (ranging from the surface to approximately $6 \mathrm{~km}$ ) during the entire event.

To examine the source of the dust plume, a threeday back-calculated air mass trajectory simulation from Wuhan that started at 1000UTC on 22, 25, and 28 April was performed using the HYSPLIT model, respectively. The air masses of five heights were simulated for each of three days. The Aura OMI AI distribution provided likely source region for this dust event (shown in Figures 3(a)-3(c)). As seen in Figure 3, some calculated backward trajectories appeared to link to the dust-outbreak source regions in a reasonable time sequence, while on some calculated backward trajectories the dust source (shown by Figures 3(a)-3(c)) is invisible. The air masses on 22 April at the different heights originated in three regions. The air mass near the surface was tracked backward to the surface of north China. The lower dust layer below $4 \mathrm{~km}$ was from the Gobi desert 1-2 days before its appearance over Wuhan. This finding is similar to the result of Kwon et al. [5], who reported that the dust from the Gobi desert always affects the lower troposphere $(<4 \mathrm{~km})$ in downstream regions. The upper layer (approximately $6 \mathrm{~km}$ ) originated from the Tibet Plateau (with an altitude of 5-6 km). However, the dust outbreak in corresponding source region is invisible because of the miss of OMI AI data. The air masses on 25 April showed that the dust layer at about 3-4 km was tracked backward to the Gobi near the border of China and Mongolia. These results suggest that the dust particles for the event are likely from Gobi of Mongolia. Additionally, another dust layer at about $3-5 \mathrm{~km}$ on 28 April was tracked backward to the Taklimakan region.

As shown in Table 2, the mean top height, base height, thickness, and centroid height of the dust layers were $5.02 \mathrm{~km}$, $1.52 \mathrm{~km}, 3.50 \mathrm{~km}$, and $3.04 \mathrm{~km}$, respectively. The standard deviations, as well as the maximum and the minimum value of the optical properties, were also shown in the table. The mean $\delta$ was 0.12 . In addition, extremely large $\delta$ of $0.2-0.3$ were observed below $5 \mathrm{~km}$ from midday on 26 April to the morning of 27 April. The $\delta_{p}(0.24)$ value was much larger than the $\delta$ value, which indicated the dominance of dust particles within the layer. The mean dust layer extinction was $0.11 \mathrm{~km}^{-1}$. As the mean extinction exceeded $0.1 \mathrm{~km}^{-1}$ in the observations, the atmosphere was very turbid. The mean dust layer AOD was 0.38 .

The vertical profiles of extinction, volume depolarization ratio, particle depolarization ratio, backscattering ratio, relative humidity, and temperature on 25 April are shown in Figure 4. The error bars represent the standard deviations. A double-layer structure with variable extinctions and $\delta$ was observed above $2 \mathrm{~km}$. The extinction and $\delta$ exhibited similar height distributions, indicating the dominance of nonspherical particles in the dust layer. The lower layer $(2.0-4.5 \mathrm{~km}) \delta$ ranged from 0.06 to 0.2 , and the extinction ranged from $0.01 \mathrm{~km}^{-1}$ to $0.08 \mathrm{~km}^{-1}$. The respective maximum $\delta(0.2)$ and extinction $\left(0.08 \mathrm{~km}^{-1}\right)$ both occurred at a height of approximately $3 \mathrm{~km}$. The upper layer $(5-8 \mathrm{~km})$ exhibited a smaller extinction and $\delta$. The extinction was extremely large below $2 \mathrm{~km}$, which was likely due to the combined contributions of dust and local aerosols. The values 


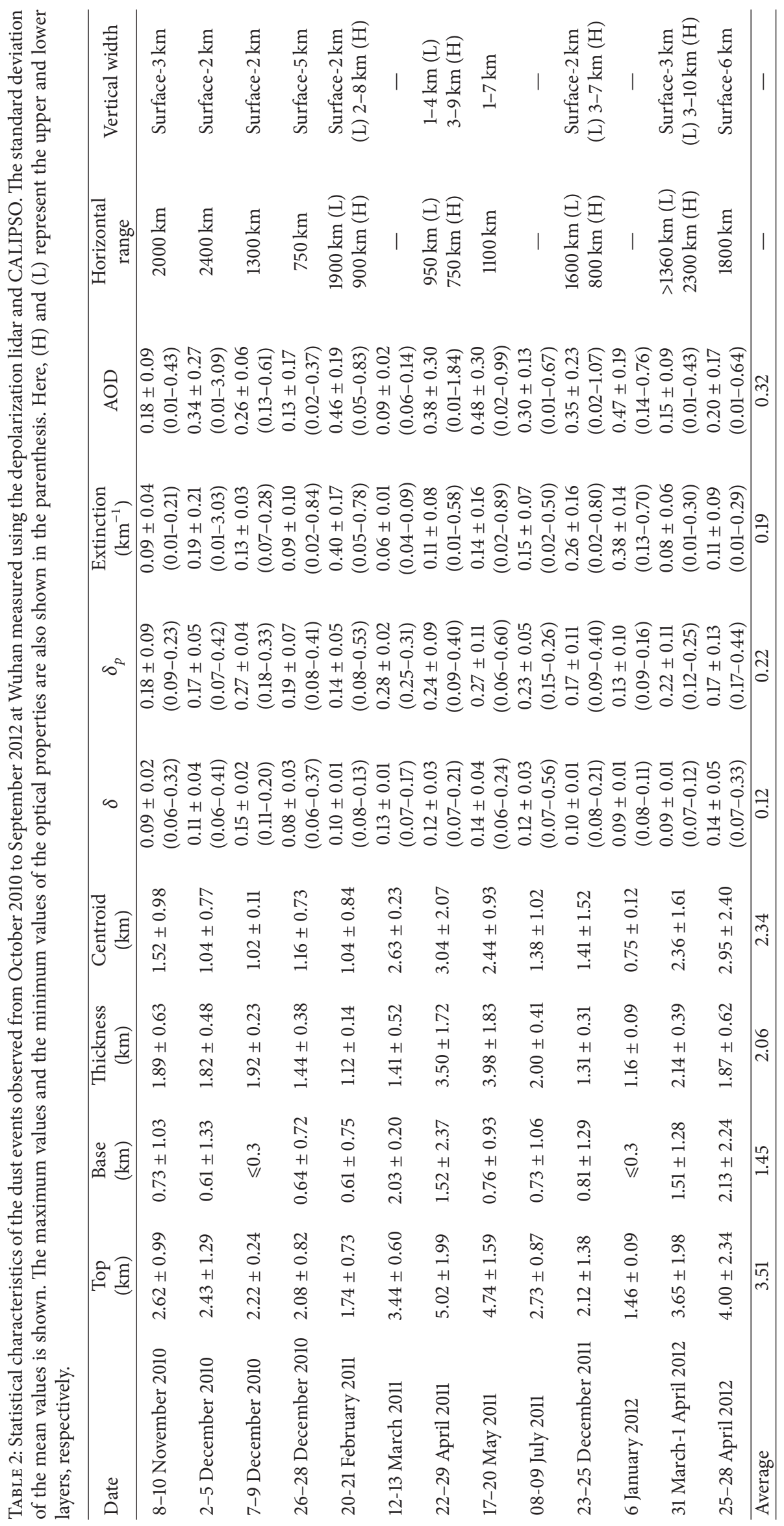




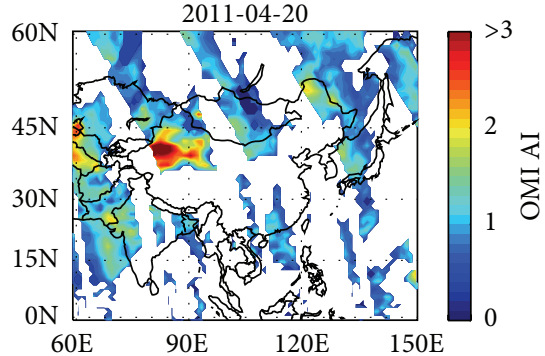

(a)

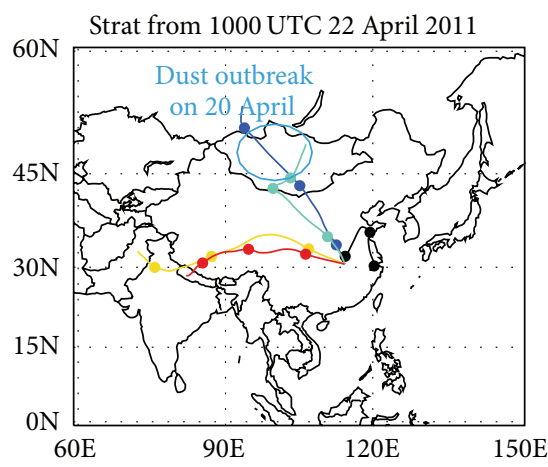

(d)

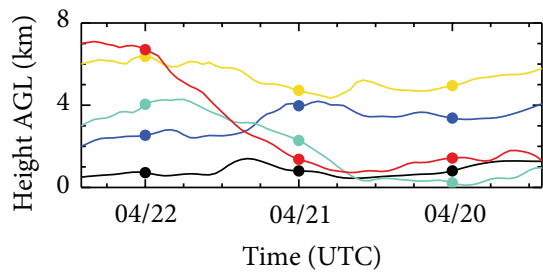

(g)

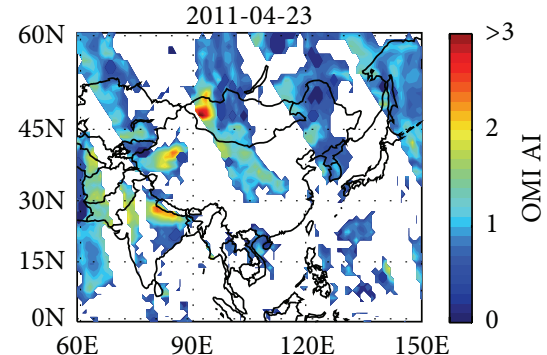

(b)

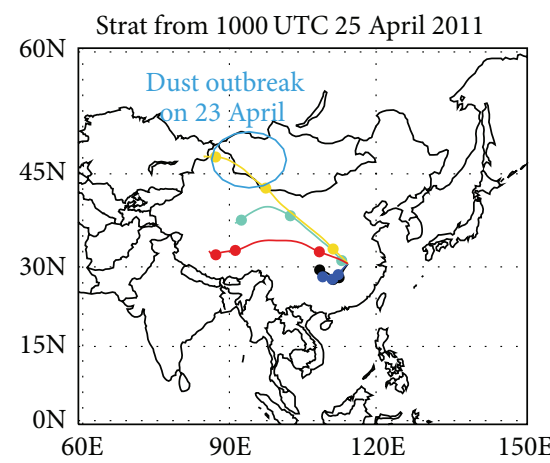

(e)

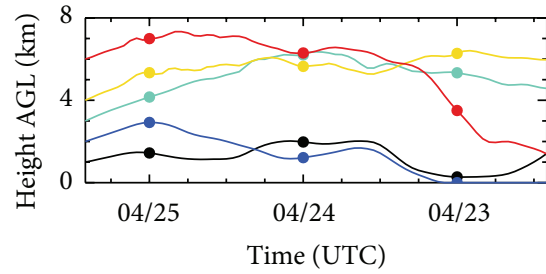

(h)

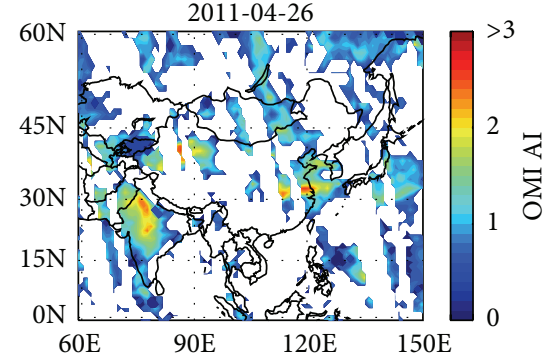

(c)

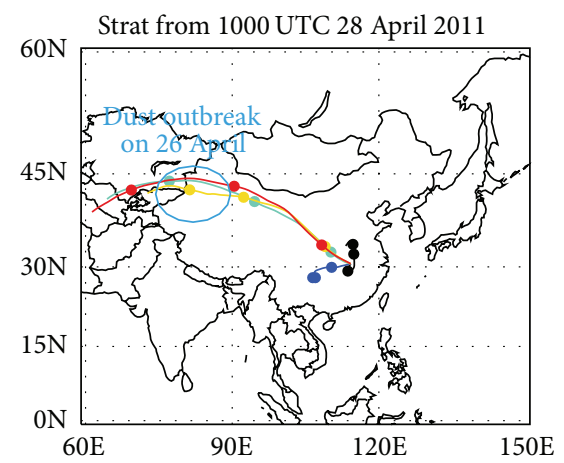

(f)

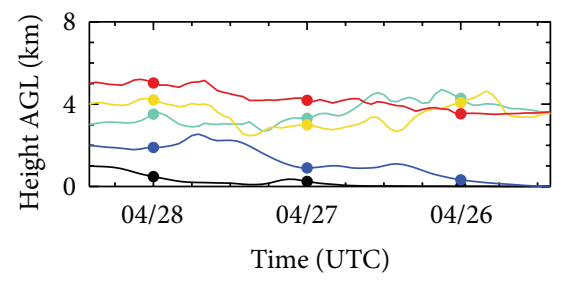

(i)

Figure 3: Aura OMI Aerosol Index (AI) distribution over East China on (a) 20 April 2011, (b) 23 April 2011, and (c) 26 April 2011. Three-day back-calculated trajectories starting at Wuhan $\left(30.5^{\circ} \mathrm{N}, 114.4^{\circ} \mathrm{E}\right)$ from $1000 \mathrm{UTC}$ on (d) 22 April 2011 (at $0.5 \mathrm{~km}, 2 \mathrm{~km}, 3 \mathrm{~km}, 6 \mathrm{~km}$, and $7 \mathrm{~km}$ ), (e) 25 April 2011 (at $1 \mathrm{~km}, 2 \mathrm{~km}, 3 \mathrm{~km}, 4 \mathrm{~km}$, and $6 \mathrm{~km}$ ), and (f) 28 April 2011 (at $1 \mathrm{~km}, 2 \mathrm{~km}, 3 \mathrm{~km}, 4 \mathrm{~km}$, and $5 \mathrm{~km}$ ), using the HYSPLIT model. The time-height display for the calculation of (d), (e), and (f) is shown in (g), (h), and (i), respectively.

of $\delta_{p}$ were very large, ranging from 0.2 to 0.4 within the lower dust layer. The BRs within the dust layer ranged from 1.1 to 2.2. The lower layer exhibited a slightly larger BR with a peak of 2.2 around $3.2 \mathrm{~km}$. The dust layer was extremely dry; that is, the $\mathrm{RH}$ was less than $10 \%$ at a height of $2-8 \mathrm{~km}$.

Figure 5 shows plots of the attenuated backscatter and volume depolarization ratio at $532 \mathrm{~nm}$, the color ratio, the vertical feature mask, the aerosol subtype mask, and the trajectory of CALIPSO observed over southeast China on 22 April. The dust plumes are denoted by the black rectangle. The dust plumes are represented by large $\delta(0.2-0.3)$ and color ratios (0.7-1.0) due to the nonspherical shape and large particle size of the dust. The double-layer structure observed using the depolarization lidar was also seen in the CALIPSO data. The aerosol subtype mask indicates that the lower layer is the mixture of dust and polluted dust and the upper layer contains only pure dust. Moreover, the CALIPSO data suggest a horizontal range of $\sim 950 \mathrm{~km}$ and $\sim 750 \mathrm{~km}$ of the layers at heights of approximately $1-4 \mathrm{~km}$ and $4-9 \mathrm{~km}$, respectively.
Specially, the height of the upper layer decreases from north to south.

3.2. Winter Dust Case: 7-9 December 2010. Figure 6 shows the temporal variation in the extinction (a) and volume depolarization ratio (b) at $532 \mathrm{~nm}$ on 7-9 December 2010, which represents a typical wintertime dust plume. Dust was observed for at least two days; however, the beginning and end of the dust event were not observed. Large $\delta$ (ranging from 0.1 to 0.25 ) and extinctions exceeding $0.1 \mathrm{~km}^{-1}$ were observed below $3 \mathrm{~km}$ during the event, which are typical optical property values in the winter.

A three-day back-calculated air mass trajectory simulation from Wuhan starting at 1000UTC on 7 December and 9 December was performed using the HYSPLIT model. As shown in Figure 7, three starting heights were simulated with the model. The results indicate that the dust plume observed below $3 \mathrm{~km}$ over Wuhan was due to the long-range transport of Gobi dust 2 days before the dust event began. The large 


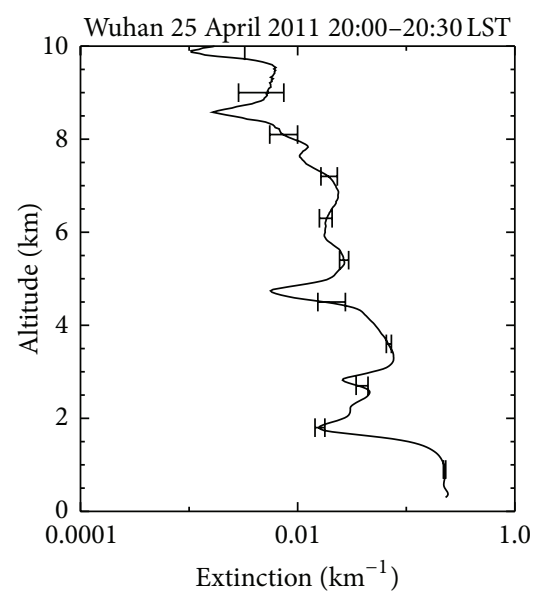

(a)

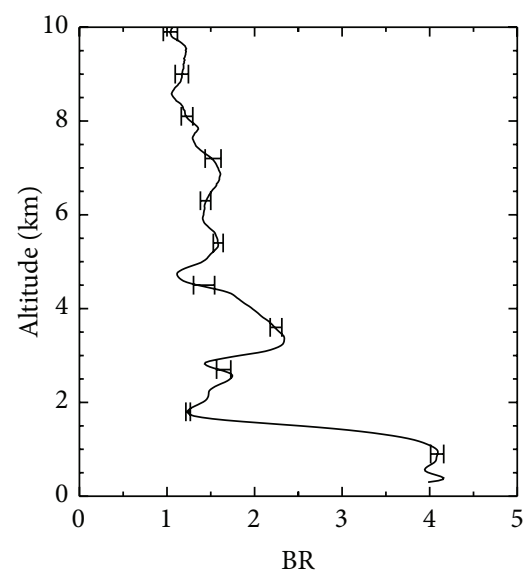

(d)

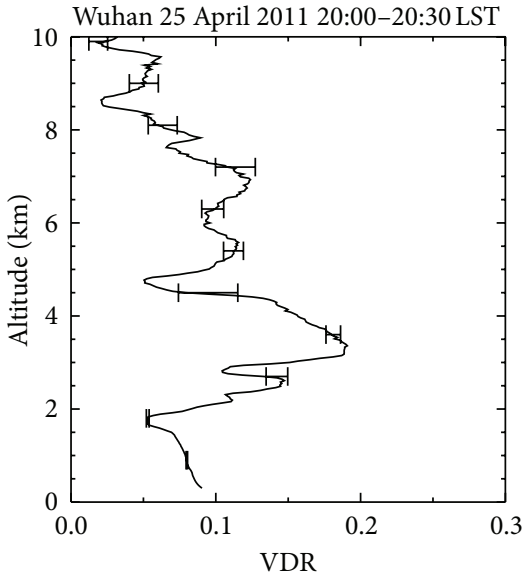

(b)

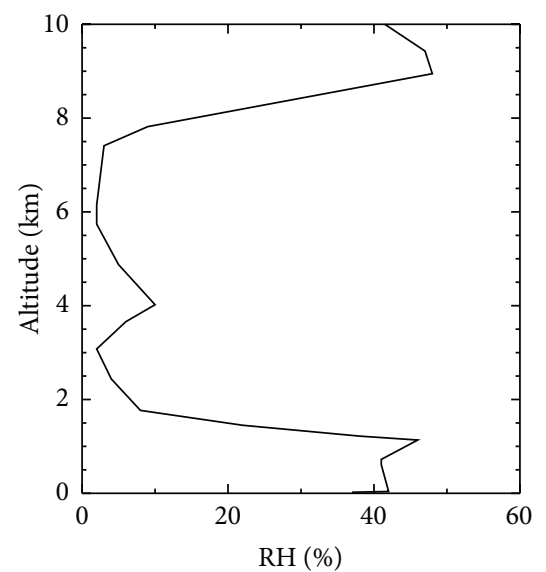

(e)

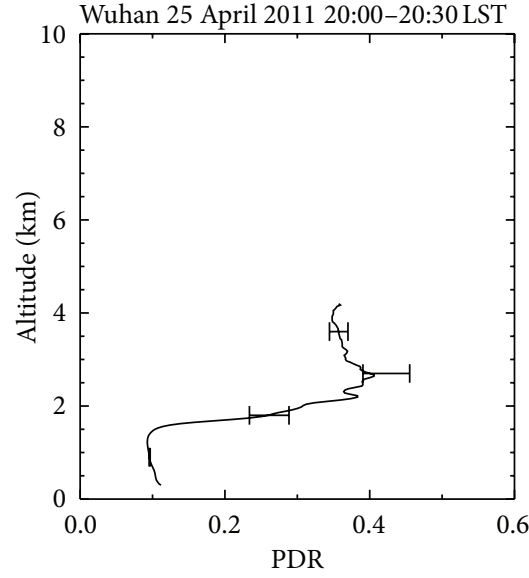

(c)

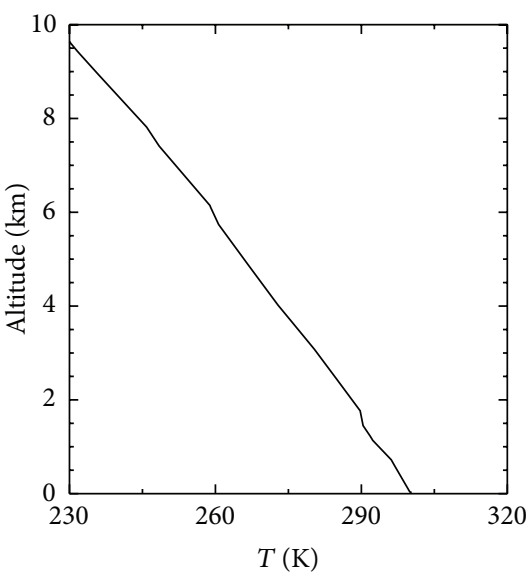

(f)

FIGURE 4: Profiles of (a) aerosol extinction, (b) volume depolarization ratio, (c) particle depolarization ratio, (d) backscattering ratio measured using the depolarization lidar, (e) relative humidity, and (f) temperature measured using radiosonde during the half hour of 20:00-20:30 LST on 25 April 2011. The error bars represent the standard deviations.

values of OMI AI (up to 2.0) indicated the occurrence of dust outbreak in Gobi region.

As shown in Table 2, the mean top height, base height, thickness, and centroid height of the dust layers are $2.22 \mathrm{~km}$, $<0.30 \mathrm{~km}, 1.92 \mathrm{~km}$, and $1.02 \mathrm{~km}$, respectively. The mean $\delta$ is 0.15 . Specifically, extremely large $\delta$ that exceed 0.2 were observed inside the dust layer from the morning of 8 December to midday on 9 December. The mean $\delta_{p}$ is 0.27 . The mean extinction $\left(0.13 \mathrm{~km}^{-1}\right)$ and the mean AOD $(0.26)$ indicate that dust layers in winter are always very turbid.

Figure 8 shows extinction, volume depolarization ratio, particle depolarization ratio, backscattering ratio, relative humidity, and temperature vertical profiles on 7 December from the polarization lidar and radiosonde. A pronounced single dust layer was observed below $2 \mathrm{~km}$ with extinctions ranging from $0.03 \mathrm{~km}^{-1}$ to $0.20 \mathrm{~km}^{-1}$ and peaking at $0.6 \mathrm{~km}$. The $\delta$ ranged from 0.07 to 0.16 within the dust layer and rapidly decreased above $1.5 \mathrm{~km}$ to nearly 0 above $2.5 \mathrm{~km}$. The $\delta_{p}$ within the dust layer ranged from 0.20 to 0.33 . The peak value of the $\delta_{p}$ appeared at $1.7 \mathrm{~km}$, which was different from the height of $0.6 \mathrm{~km}$ for aerosol extinction; thus, anthropogenic aerosols within the PBL contributed greatly below $1 \mathrm{~km}$. The RH decreased with height from $40 \%$ at the surface to only $2 \%$ above $2.5 \mathrm{~km}$. RHs of $20-50 \%$ were typical in wintertime dust layers.

Figure 9 shows plots of the attenuated backscatter and volume depolarization ratio at $532 \mathrm{~nm}$, the color ratio, the vertical feature mask, the aerosol subtype mask, and the trajectory of CALIPSO observed over southeast China on 7 December. Dust plumes with large $\delta(0.2-0.3)$ and color ratios (0.7-1.0) are denoted with a black rectangle. The single dust layer observed from the surface to $2 \mathrm{~km}$ displays the same characteristics as those seen in the ground-based lidar observations. Dust plumes below a height of $3 \mathrm{~km}$ frequently occur between $30^{\circ} \mathrm{N}$ and $40^{\circ} \mathrm{N}$ over mainland China in the winter. The dust layers typically have a horizontal range of $1300 \mathrm{~km}$. The CALIPSO data confirm that the high $\delta$ observed at this low height using ground-based lidar was not caused by local floating dust but rather by a long-range transport dust plume. 


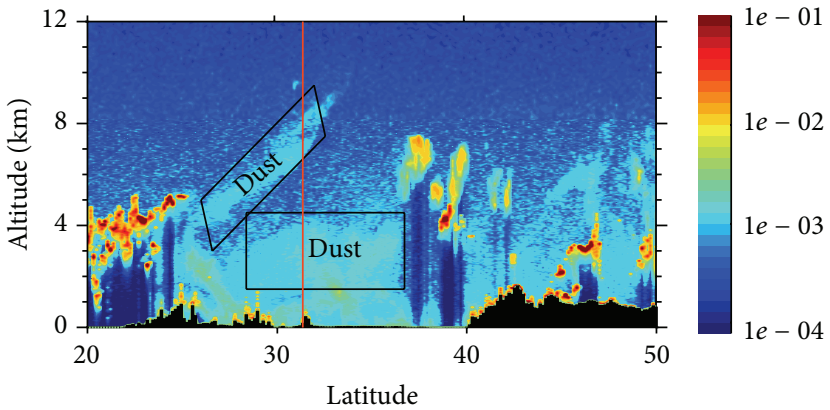

(a) Attenuated backscatter coefficient $\left(\mathrm{km}^{-1} \mathrm{sr}^{-1}\right)$

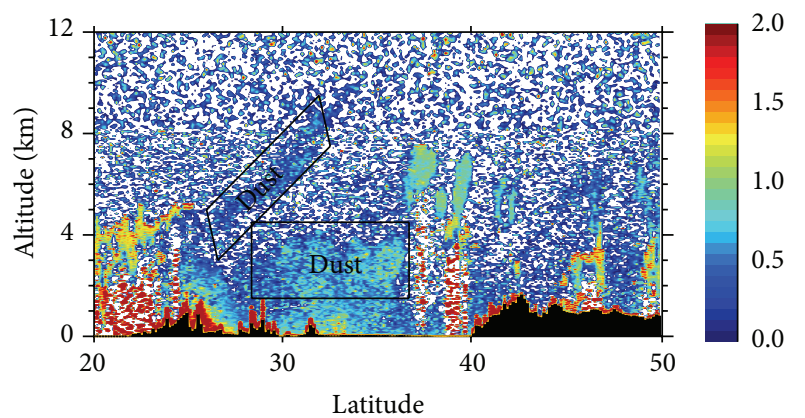

(c) Color ratio

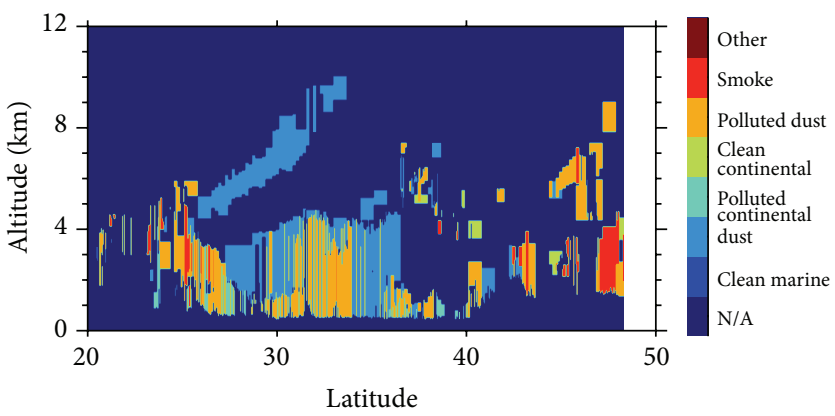

(e) Aerosol subtypes

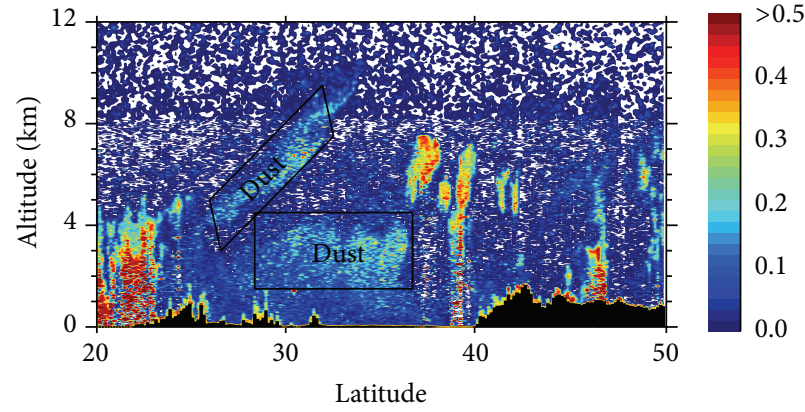

(b) Volume depolarization ratio

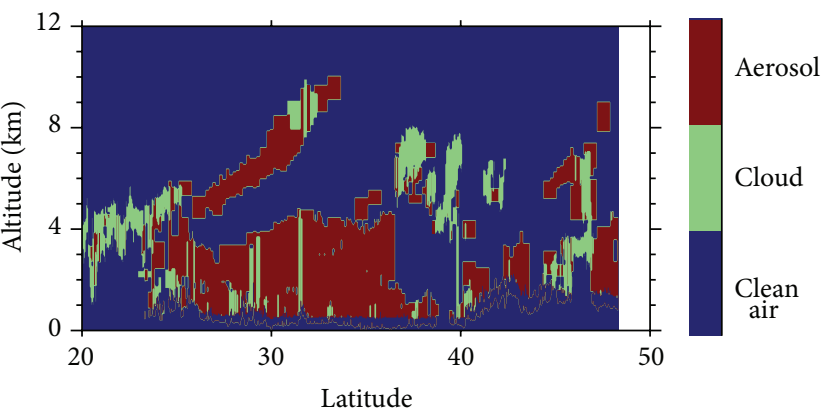

(d) Vertical feature mask

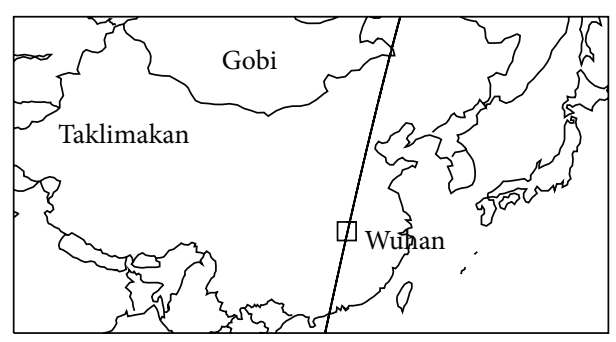

(f) Trajectory of CALIPSO

FIGURE 5: CALIPSO altitude-orbit cross-section measurements of (a) $532 \mathrm{~nm}$ total attenuated backscatter coefficient, (b) volume depolarization ratio, and (c) $1064 \mathrm{~nm} / 532 \mathrm{~nm}$ backscatter color ratio; the figure shows the (d) vertical feature mask, (e) aerosol subtype mask, and (f) CALIPSO trajectory in the map (the corresponding orbit is 2011-04-22T18-16-45) over southeast China between $20^{\circ}$ and $50^{\circ} \mathrm{N}$ on 22 April 2011. The red line (see (a)) marks the location of Wuhan. The locations of Taklimakan, Gobi, and Wuhan are marked in (f).

3.3. Statistical Characteristics of Dust over Wuhan. Table 2 lists the characteristics of the 13 dust events extracted from the depolarization lidar measurements collected between October 2010 and September 2012. All of the selected events spanned at least 10 hours and exhibited no complex mixing between dust and clouds. Table 2 lists the mean top height, base height, thickness, centroid height, volume depolarization ratio, particle depolarization ratio, extinction, and AOD of these dust events. The standard deviations, maximum and minimum values, are also shown in the table. The average dust layer height was $1.45-3.51 \mathrm{~km}$; the maximum and minimum heights were approximately $5.02 \mathrm{~km}$ and less than $0.3 \mathrm{~km}$, respectively. The average centroid height was $2.34 \mathrm{~km}$, which was the altitude of highest dust loading. The $\delta$ ranged from 0.09 to 0.15 ; the mean was 0.12 . The $\delta_{p}$ ranged from 0.13 to 0.33 ; the mean was 0.22 . The extinctions ranged from $0.06 \mathrm{~km}^{-1}$ to $0.40 \mathrm{~km}^{-1}$; the mean was $0.19 \mathrm{~km}^{-1}$. Moreover, the AODs ranged from 0.09 to 0.48 ; the mean was 0.32 . The vertical and horizontal ranges of the dust plumes obtained from the CALIPSO data are also shown in Table 2. The retrieval failures in 4 cases were due to missing CALIPSO data or the failure to identify a dust plume due to the presence of clouds. Among the remaining 9 cases, 4 cases exhibit a double-layer structure. The horizontal ranges of the dust plumes were approximately $750 \mathrm{~km}$ to $2400 \mathrm{~km}$. The dust plume thicknesses ranged from approximately $2 \mathrm{~km}$ to $7 \mathrm{~km}$.

Dust emissions over Wuhan are frequent during the spring and winter. Comparisons of the vertical distribution and optical properties of dust between the two seasons are listed in Table 3. The dust layer was higher in the spring 
TABLE 3: Comparison of dust properties over Wuhan during spring and winter. The standard deviations of the mean values are shown. The maximum values and the minimum values of the optical properties are also shown in the parenthesis.

\begin{tabular}{|c|c|c|c|c|c|c|c|c|}
\hline Time & $\begin{array}{c}\text { Top } \\
(\mathrm{km})\end{array}$ & $\begin{array}{l}\text { Base } \\
(\mathrm{km})\end{array}$ & $\begin{array}{c}\text { Thickness } \\
(\mathrm{km})\end{array}$ & $\begin{array}{c}\text { Centroid } \\
(\mathrm{km})\end{array}$ & $\delta$ & $\delta_{p}$ & $\begin{array}{c}\alpha_{a} \\
\left(\mathrm{~km}^{-1}\right)\end{array}$ & AOD \\
\hline Spring & $4.17 \pm 0.68$ & $1.59 \pm 0.54$ & $2.58 \pm 0.97$ & $2.68 \pm 0.66$ & $\begin{array}{c}0.12 \pm 0.02 \\
(0.09-0.14)\end{array}$ & $\begin{array}{l}0.27 \pm 0.04 \\
(0.22-0.33)\end{array}$ & $\begin{array}{l}0.10 \pm 0.03 \\
(0.06-0.14)\end{array}$ & $\begin{array}{c}0.26 \pm 0.13 \\
(0.09-0.48)\end{array}$ \\
\hline Winter & $2.01 \pm 0.35$ & $0.54 \pm 0.20$ & $1.46 \pm 0.31$ & $1.07 \pm 0.62$ & $\begin{array}{c}0.10 \pm 0.02 \\
(0.08-0.15)\end{array}$ & $\begin{array}{c}0.18 \pm 0.05 \\
(0.13-0.27)\end{array}$ & $\begin{array}{c}0.24 \pm 0.14 \\
(0.09-0.40)\end{array}$ & $\begin{array}{l}0.34 \pm 0.15 \\
(0.13-0.47)\end{array}$ \\
\hline
\end{tabular}

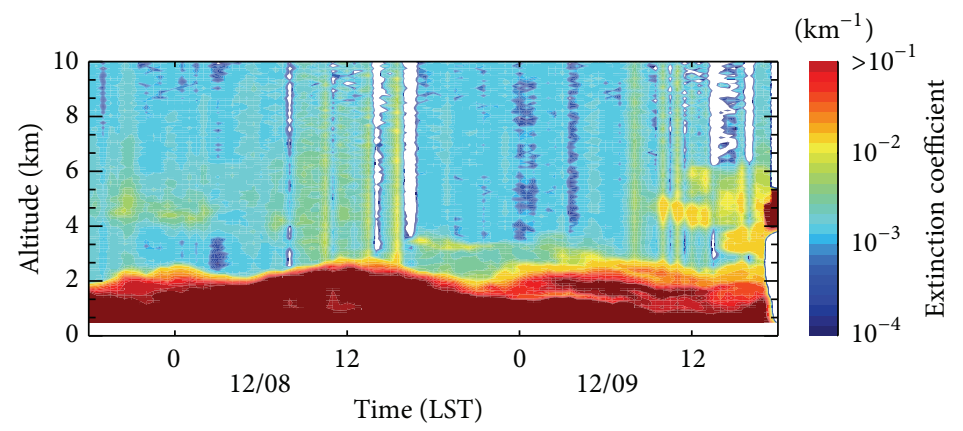

(a)

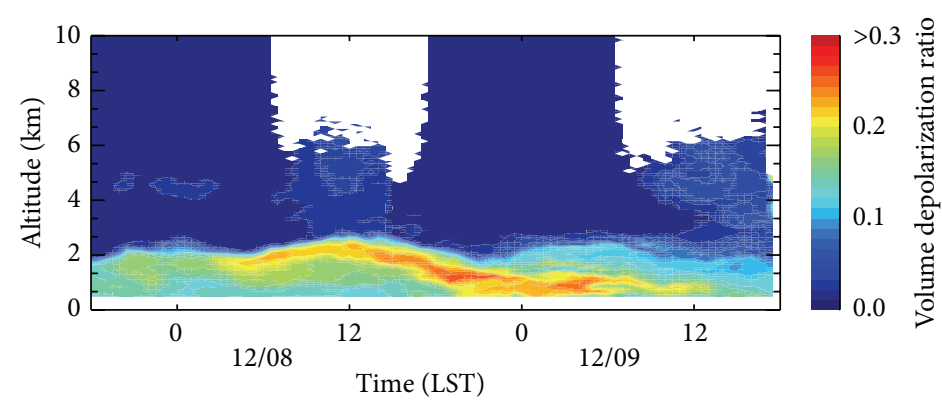

(b)

FIgURE 6: Same as Figure 2, except for the date, 7-9 December 2010.

(approximately $1.59-4.17 \mathrm{~km}$ ) than winter (approximately $0.54-2.01 \mathrm{~km})$. The mean centroid height of $2.68 \mathrm{~km}$ in the spring was higher than in winter $(1.07 \mathrm{~km})$. Moreover, the dust layer was thicker in the spring $(2.58 \mathrm{~km})$ than in winter $(1.46 \mathrm{~km})$. The mean $\delta$ was slightly larger in the spring $(0.12)$ than in winter $(0.10)$. The mean $\delta_{p}$ was much larger in spring (0.27) than in winter (0.18), indicating the greater nonsphericity of dust particles in the spring. In contrast, the mean extinction in the winter $\left(0.24 \mathrm{~km}^{-1}\right)$ was 1.4 times larger than in spring $\left(0.10 \mathrm{~km}^{-1}\right)$. Furthermore, the mean AOD in the winter (0.34) was $31 \%$ larger than in spring (0.26). Based on the CALIPSO data, the dust plumes were thicker and higher in the spring, and the plumes were generally thinner and closer to the surface in the winter.

To obtain more information on the microphysical character of dust aerosols, the particle size distribution (PSD) of the aerosols was computed using sun photometer (CE318) measurements [41]. Figure 10 shows the retrieved aerosol size distributions for the dust cases in spring (blue) and winter (red). The PSD was bimodal with the peak of the coarse model at $2.0 \mu \mathrm{m}$ in both seasons, indicating the typical particle radius of dust aerosols. The peak of the fine model was approximately $0.13 \mu \mathrm{m}$ in winter and $0.07 \mu \mathrm{m}$ in spring.

Similar bimodal distributions were also observed in spring and winter in Wuhan by Gong et al. [43]. The fine and coarse modes in both spring and winter peaked at $0.2 \mu \mathrm{m}$ and $4 \mu \mathrm{m}$, respectively. The particle size distribution (PSD) value was larger in coarse mode in winter than in spring. Liu et al. [44] observed two spring dust events at Taihu, China, in 2009. The fine and coarse modes in the PSD observed by sun photometer peaked at $0.1 \mu \mathrm{m}$ and $2 \mu \mathrm{m}$, respectively. Liu et al. [45] presented the seasonal mean PSD based on the sun photometer observations from 2006 to 2009 at Taihu. They noticed a similar bimodal distribution during winter and spring with nearly the same peaks in both fine and coarse modes. The fine and coarse modes were observed at 0.1-0.2 $\mu \mathrm{m}$ and 3.0-4.0 $\mu \mathrm{m}$, respectively. These observational results (bimodal distribution with a fine mode at $0.1-0.2 \mu \mathrm{m}$ and a coarse mode at $2.0-4.0 \mu \mathrm{m}$ ) are similar to that given in the current work. A main reason for the similarity is 


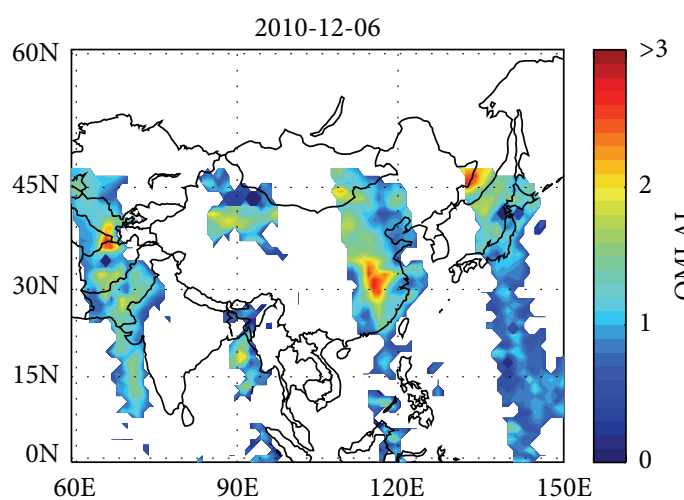

(a)

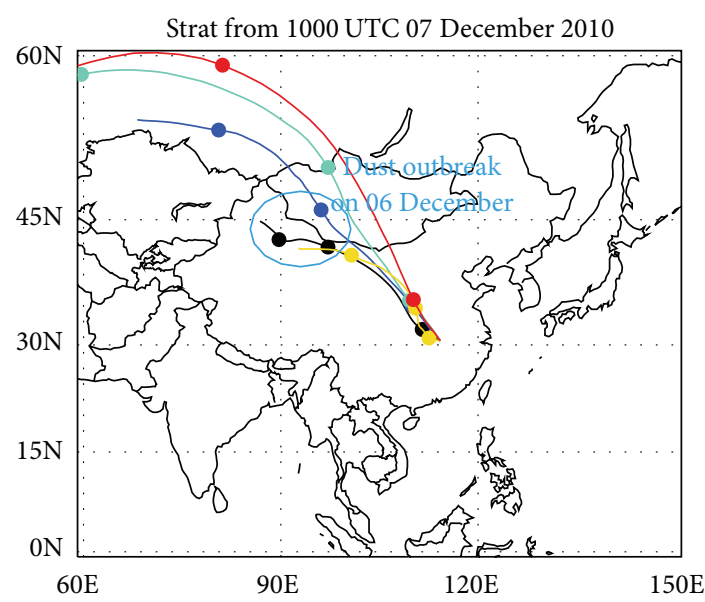

(c)

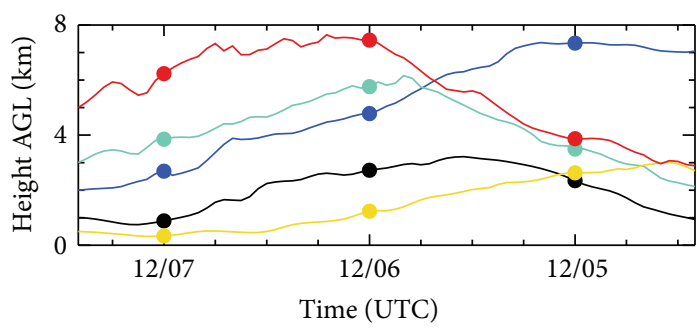

(e)

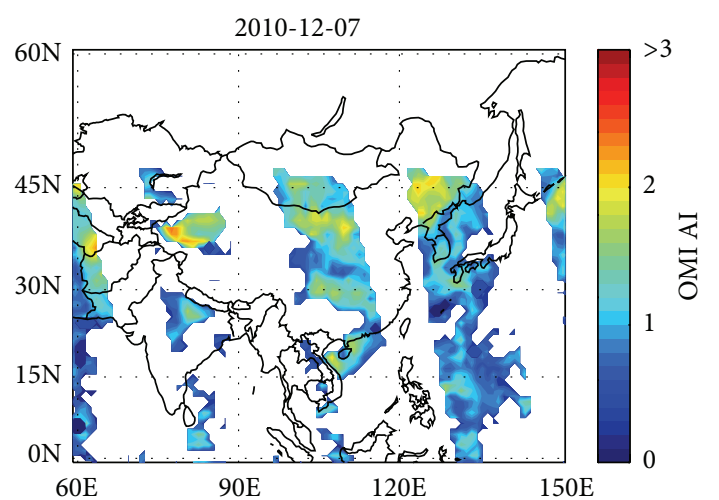

(b)

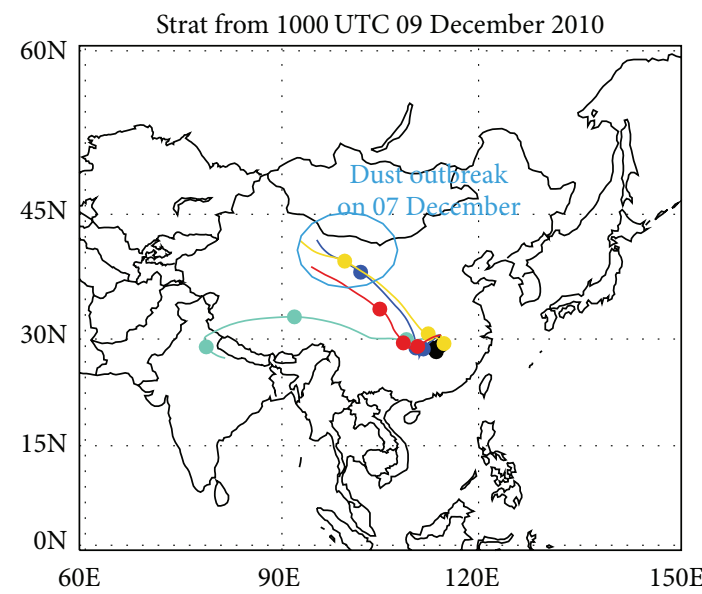

(d)

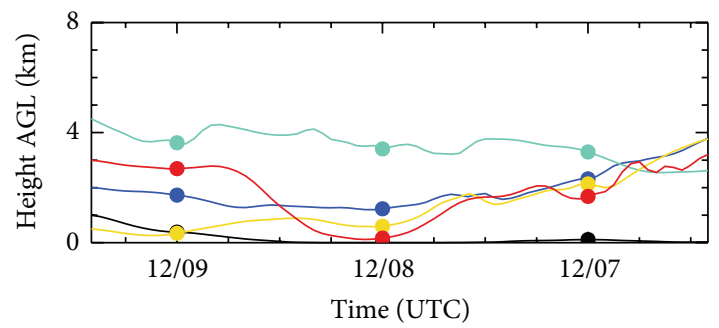

(f)

Figure 7: Aura OMI Aerosol Index (AI) distribution over East Asia on (a) 6 December 2010 and (b) 7 December 2010. Three-day backcalculated trajectories starting at Wuhan $\left(30.5^{\circ} \mathrm{N}, 114.4^{\circ} \mathrm{E}\right)$ from $1000 \mathrm{UTC}$ on (c) 07 December 2010 (at $0.5 \mathrm{~km}, 1 \mathrm{~km}, 2 \mathrm{~km}, 3 \mathrm{~km}$, and $5 \mathrm{~km}$ ) and (d) 09 December 2010 (at $0.5 \mathrm{~km}, 1 \mathrm{~km}, 2 \mathrm{~km}, 3 \mathrm{~km}$, and $4.5 \mathrm{~km}$ ), using the HYSPLIT model. The time-height display for the calculation of (c) and (d) is shown in (e) and (f), respectively.

that Wuhan has weather condition and geographical latitude similar to the sites where the earlier observations were made. However, the observations near the dust source region of Asian dust showed rather different results. Zheng et al. [46] observed the PSD at Dunhuang, China, from January 1999 to March 2001. The mean PSD in spring and winter had a fine mode with a central radius of $\sim 0.25 \mu \mathrm{m}$, and a coarse mode with a central radius of $\sim 7.7 \mu \mathrm{m}$. The central radius of coarse mode was remarkably larger than the downstream regions of observations. It is seemed that extremely large dust particles were removed during the dust plume transport.

\section{Discussion}

4.1. Different Characteristics in Spring and Winter. As mentioned above, the dust layers are higher in spring than in winter. Two likely explanations are presented below. First, Asian dust is generated by cold air outbreaks and driven by westerly jets. Asian dust outbreaks are more intense in the spring than in winter due to the higher frequency of strong winds. Kurosaki and Mikami [47] found good agreement in the yearly variations and spatial distributions between the surface wind and dust outbreaks over East Asia during the period 2000-2002. The stronger surface winds in the 


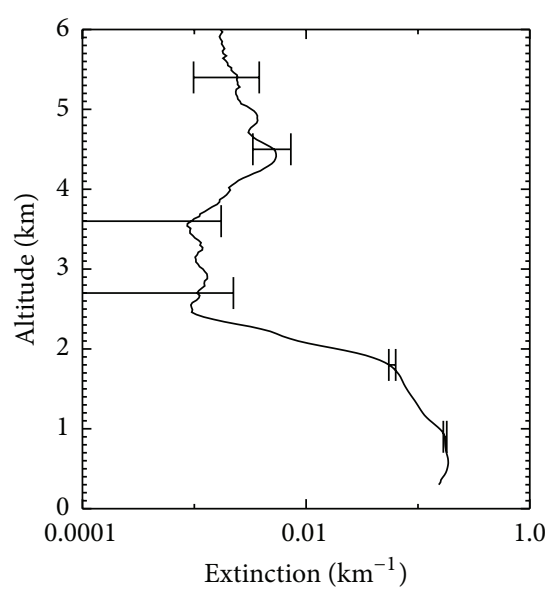

(a)

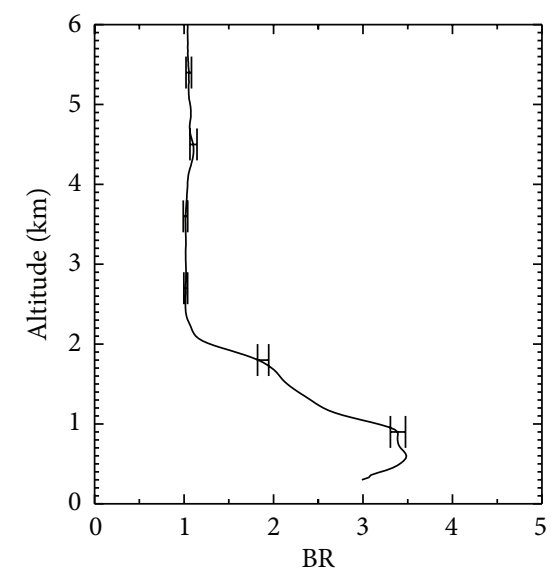

(d)

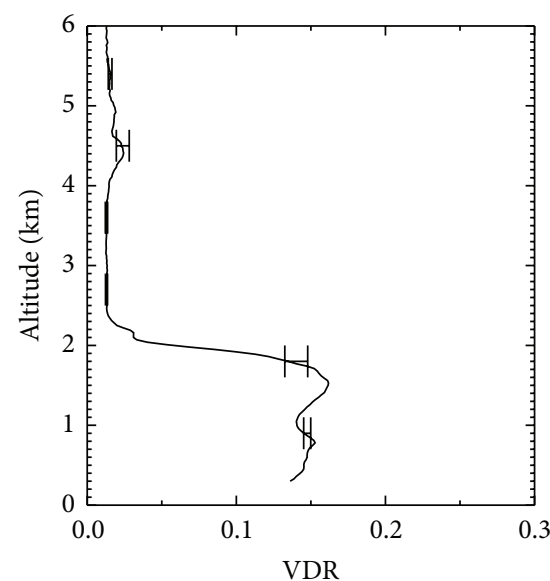

(b)

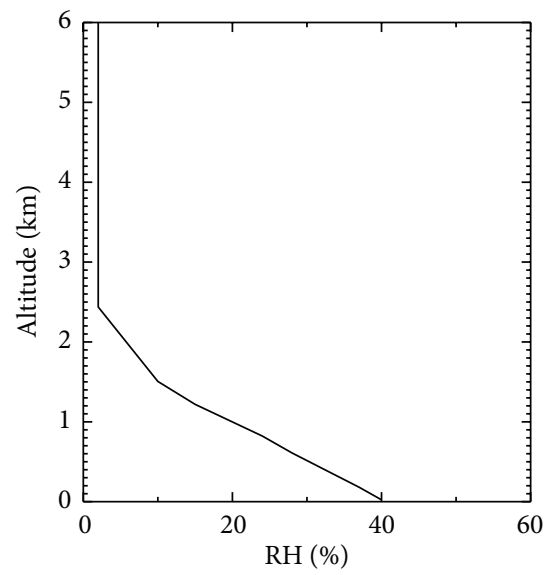

(e)

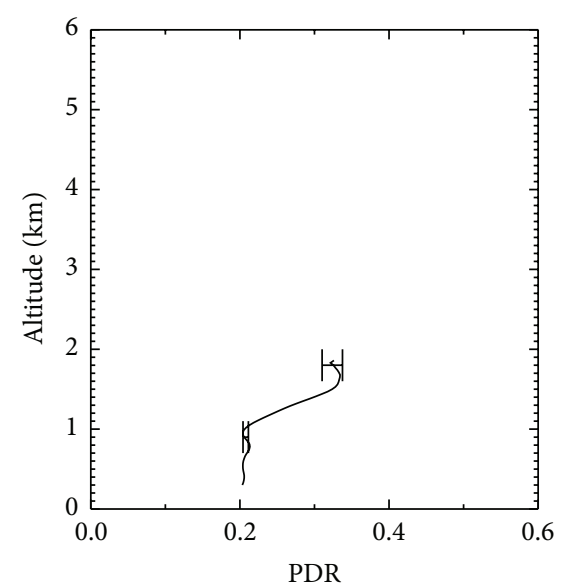

(c)

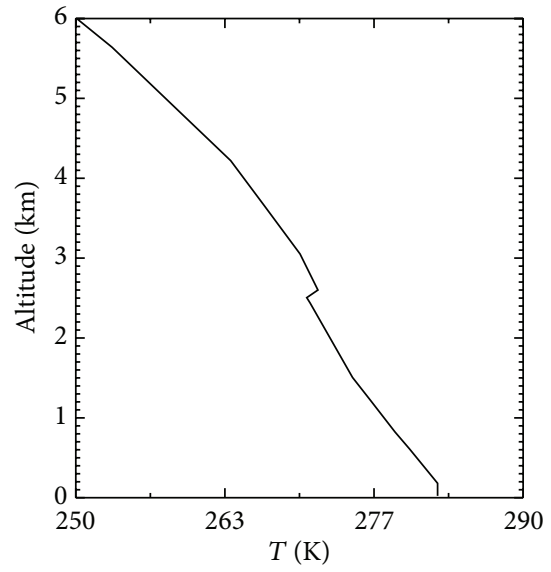

(f)

FIGURE 8: Same as Figure 4, except for the dates, 7 December 2010.

spring effectively carry the desert dust particles to higher altitudes in the free troposphere. The elevated dust aerosols are then transported over long distances. As a result, the spring dust plume over downstream regions (such as Wuhan) is higher than the winter plume. Second, the temperature inversion that occurs frequently in the lower troposphere over Wuhan during the winter restricts the vertical convective transportation of dust and other aerosols in the lower troposphere. Zhang et al. [48] observed two lower tropospheric inversion layers over Yichang $\left(111^{\circ} 18^{\prime} \mathrm{E}, 30^{\circ} 42^{\prime} \mathrm{N}\right)$ in January 2007. Their observations reveal the inversion layers are closely related to the intensive inertial gravity waves propagation in winter tropospheric jets. The temperature profiles from the radiosondes were statistically analyzed over Wuhan. Of the 27 radiosondes launched during the 6 winter cases, a temperature inversion (a layer thicker than $0.12 \mathrm{~km}$ with a lapse rate greater than $-2 \mathrm{~K} / \mathrm{km}$ ) at heights of $1.5-3 \mathrm{~km}$ was observed in $60 \%$ of the radiosonde measurements. Of the 32 radiosondes launched during the 5 spring cases, a temperature inversion in the same region was observed in only $28 \%$ of the radiosonde measurements. The probability of a temperature inversion in the winter was approximately twice that of spring. Therefore, it is likely that the dust particles are inhibited from leaving the lower troposphere via convective transport due to the restriction caused by the temperature inversion in the winter.

As shown in Table 3, the mean dust layer extinction and AOD in the spring are $0.10 \mathrm{~km}^{-1}$ and 0.26 , respectively. These values increase by $140 \%$ and $31 \%$ in the winter, respectively. What caused the larger extinction and AOD in the winter? Our conjecture is that the lower dust plume height in the winter provides more opportunities for effective mixing of dust particles and local pollution aerosols near the surface. Consequently, the large extinction and AOD observed in the winter are caused by the combined contributions of dust particles and other aerosol types near the surface. In contrast, the mean base height of $1.59 \mathrm{~km}$ in the spring reduces the probability of the mixing of dust and near-ground aerosols.

The mean $\delta$ of 0.10 in winter is slightly smaller than that in spring (0.12). Particularly, the value of $\delta_{p}$ in winter $(0.18)$ is much smaller than that in spring (0.27). This finding is potentially attributed to the mixing of dust particles and water vapor in the lower troposphere. Figure 11 shows the correlation between $\delta_{p}$ and $\mathrm{RH}$ in the spring and winter. 


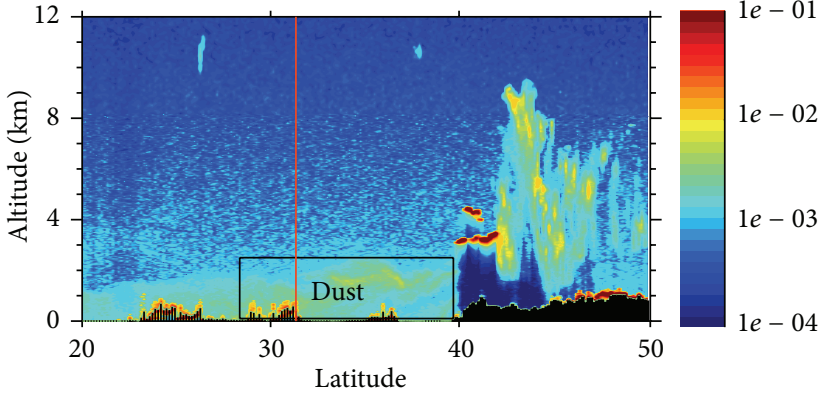

(a) Attenuated backscatter coefficient $\left(\mathrm{km}^{-1} \mathrm{sr}^{-1}\right)$

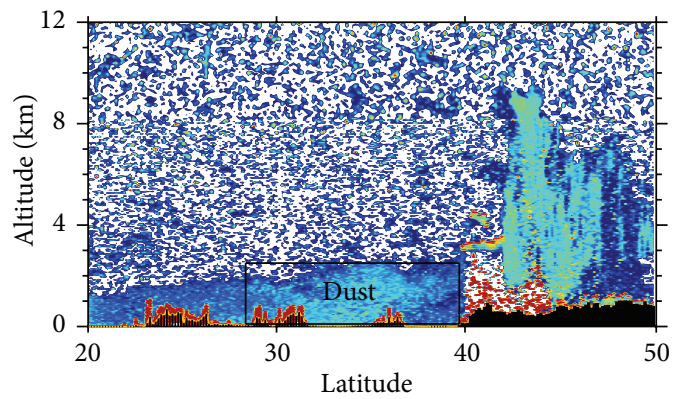

(c) Color ratio

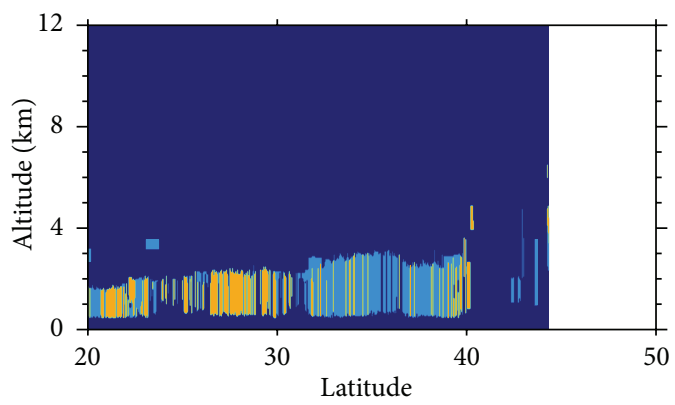

(e) Aerosol subtypes

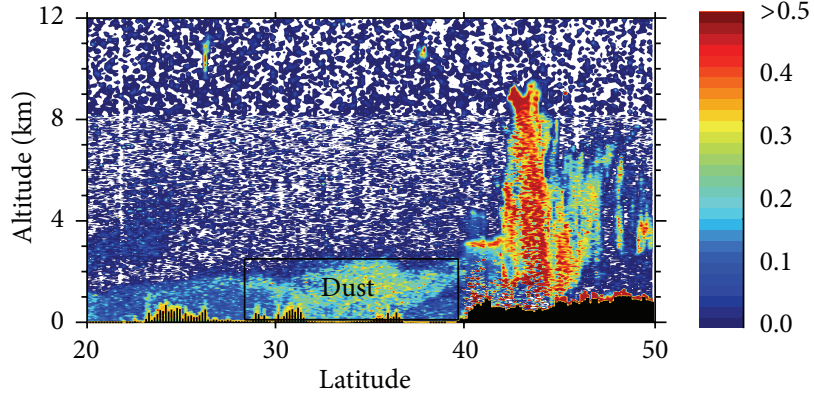

(b) Volume depolarization ratio
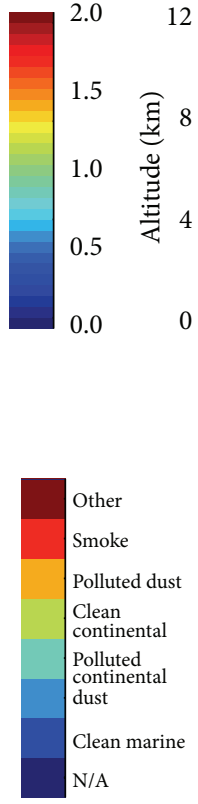

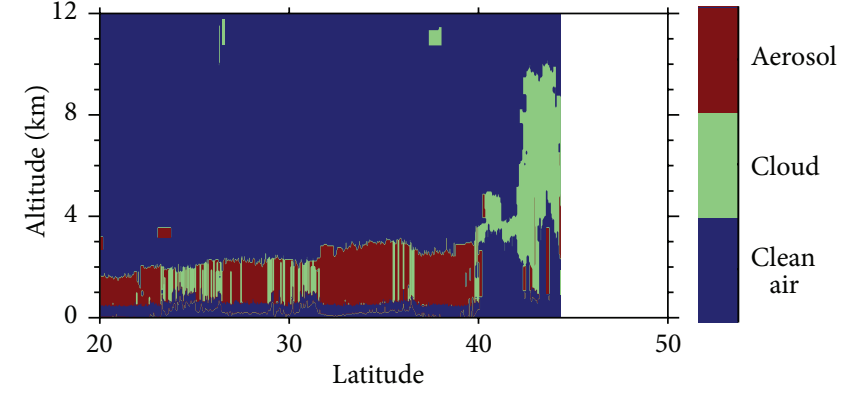

(d) Vertical feature sask

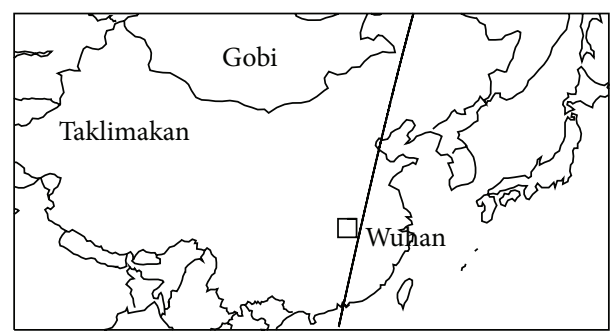

(f) Trajectory of CALIPSO

FIGURE 9: Same as Figure 5, except for the date, 8 December 2010. The corresponding CALIPSO orbit is 2010-12-08T18-00-13.

The $\delta_{p}$ and $\mathrm{RH}$ are weakly linearly correlated in the spring (correlation coefficient of -0.19); however, the $\delta_{p}$ and $\mathrm{RH}$ exhibit a strong, negative linear correlation in the winter (correlation coefficient of -0.71 ), which indicates the strong effect of RH on the $\delta_{p}$. In the winter, plenty of dust aerosols transported at a relatively low horizontal velocity and low height are determined by regional weather systems and topography. Therefore, dust particles have abundant time to mix with the local water vapor and pollution aerosols. Dust particles may interact with acidic pollutants (such as $\mathrm{SO}_{2}$ and $\mathrm{NO}_{x}$ ) under high $\mathrm{RH}$ conditions. The neutralization process (such as the reaction between $\mathrm{CaCO}_{3}$ and $\mathrm{H}_{2} \mathrm{SO}_{4}$ ) promotes the hygroscopic growth of dust particles [16, 25]. Under high relative humidity conditions, activated dust particle would experience hygroscopic growth to produce enhanced scattering and extinction $[25,26,49]$, as well as reducing the depolarization ratio $[16,50,51]$. Murayama et al. [50] observed the $\delta_{p}$ decreased with the increasing of RH. Ikegami et al. [51] found that dust particles could be covered with sulfuric acid solution in the troposphere. The internal mixture would lead to the change of depolarization ratio and its dependence to $\mathrm{RH}$.

With the prevailing westerlies, most Asian dust events occur in the spring [14-17]; few events occur in the winter [52, 53]. Kim et al. [53] and Kim [54] observed that more than $80 \%$ of dust emissions occur in the spring, based on long-term observations made in Korea, which indicates that dust affects Japan and Korea mostly in the spring. In contrast, approximately half of the dust events over Wuhan are observed in the winter, indicating that winter is another season when plenty of intrusive dust plumes occur. Two years of CALIPAO level 1B data (the same period of the polarization lidar observations) were employed to validate the frequency of seasonal dust events (Table 4). Two regions were chosen for the comparison: southeast China $\left(28^{\circ}-33^{\circ} \mathrm{N}, 109^{\circ}-119^{\circ} \mathrm{E}\right)$ and the area of Korea and Japan $\left(33^{\circ}-38^{\circ} \mathrm{N}, 127^{\circ}-137^{\circ} \mathrm{E}\right)$. Wuhan is located in the middle of the selected southeast China region. Cloud screening was first performed using CALIPSO level 2 
TABLE 4: Comparison of seasonal dust occurrences in southeast China $\left(25-35^{\circ} \mathrm{N}, 110-118^{\circ} \mathrm{E}\right)$ and Korea-Japan $\left(33^{\circ}-38^{\circ} \mathrm{N}, 127^{\circ}-\right.$ $137^{\circ} \mathrm{E}$ ), based on CALIPSO data from October 2010 to September 2012.

\begin{tabular}{lcccc}
\hline Dust occurrence & Spring & Summer & Fall & Winter \\
\hline Southeast China & 0.73 & 0.37 & 0.56 & 0.68 \\
Korea-Japan & 0.56 & 0.13 & 0.25 & 0.26 \\
\hline
\end{tabular}

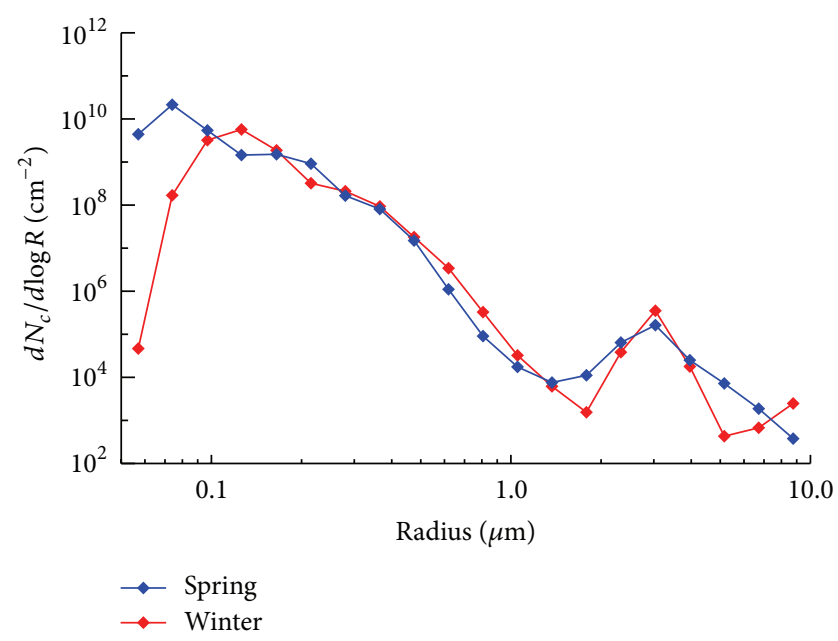

FIGURE 10: Particle size distribution of aerosols over Wuhan during the dust cases in spring and winter, derived from sun photometer data (CE-318).

$333 \mathrm{~m}$ and $5 \mathrm{~km}$ cloud layer products following the method of Liu et al. [23]. After screening for clouds, there remained 6230 and $85375 \mathrm{~km}$ profiles for southeast China and the Japan-Korea area, respectively. In southeast China, the dust occurrence is highest in the spring and slightly lower in winter; the frequency is lowest in the summer. The KoreaJapan region exhibits similar seasonal variations; however, for every season, the occurrence of dust is relatively less there than in southeast China. There is another difference between the two regions. The dust occurrence probability over southeast China in the winter $(0.68)$ is nearly the same as that as in the spring (0.73). However, the dust occurrence probability in the Korea-Japan region in the winter $(0.26)$ is slightly less than half of that in the spring (0.56). These findings based on two years of CALIPSO data agree with other reports from Korea and Japan and the results from our ground-based depolarization lidar. In the winter, dust from Mongolia and northern China is always entrained by more southeastward cold frontal systems.

4.2. Comparisons of Optical Properties with Other Observations. The volume depolarization ratios listed in Table 2 are smaller than those of other Asian dust events reported in previous studies. The dust aerosol volume depolarization ratios are 0.21 on the Tibet Plateau [20], 0.17-0.25 in Japan [15], 0.18 in Korea [55], 0.35 in Beijing [56], and 0.19 in Taiwan [25]. The dust plumes are always transported at a low horizontal velocity as they leave the westerly jet and move southward to Wuhan. Enough time is provided for the dust particles to externally and internally mix with other urban aerosols. Cottle et al. [57] observed the maximum volume depolarization ratio within the dust layers reduced substantially from 0.27 over Vancouver to 0.15 over Egbert by the time the dust layers travelled across North America during April 2010. They explained this finding that was the result of continued loss of dust, external mixing with the background aerosol layer or more likely a combination of both. Large quantity of pollutant (such as soot, sulfate, and nitrate) is released due to the heating from November to next March over northern China. The atmospheric diffusion condition in winter is usually unfavorable, which causes the persistence of aerosols aggregation [58]. As a result, a plenty of anthropogenic aerosols intrude into the transported dust plume and weaken its overall nonspherical shape property. Local emissions from vehicles and coal-fired power plants, industrial waste gas, and city construction plant dust yield abundant local pollution aerosols over Wuhan and nearby areas. Thus the lidar-observed dust plumes over Wuhan were actually mixed with those aerosols that intruded into during transport and were produced locally. Chemical processes may occur between the dust particles and the acidic pollution under suitable $\mathrm{RH}$ conditions. Then, the hydrophobic dust particles may become hydrophilic [25]. These mixing and chemical processes may make the dust particles more spherical (reducing the particle depolarization ratio).

The extinctions measured over Wuhan are larger than those measured at other sites. The mean extinction measured on 29-31 May 2008 in Seoul, Korea, was $0.08-0.12 \mathrm{~km}^{-1}$. Further statistical dust characteristics were examined based on 14 dust events occurring between April 2006 and March 2009. The extinctions ranged from $0.10 \mathrm{~km}^{-1}$ to $0.20 \mathrm{~km}^{-1}$; the mean was $0.14 \mathrm{~km}^{-1}$ [22]. A similar extinction range (0.02$0.23 \mathrm{~km}^{-1}$ ) was measured using Raman lidar in Thessaloniki, Greece, based on 12 cases observed during the period 20012002 [59]. The mean AOD (0.32) in the dust layer over Wuhan is relatively large compared to other downstream regions. Liu et al. [39] observed an extensive dust storm originating on 17 August 2006 in North Africa using CALIPSO lidar. Dust layer AODs (0.08-0.09) were measured on 28 August 2006 in the Gulf of Mexico using the NASA high spectral resolution lidar. Papayannis et al. [60] measured dust layer AODs (0.100.25) using 8 lidar stations in Europe from May 2000 to December 2002. The extinctions and AODs over Wuhan were larger than those reported in other studies, which was caused by high local aerosol loadings. Pure dust particles are removed over time with continual sedimentation during transport. Hence, dust particles contribute increasingly less to the total extinction and AOD, while other aerosols inside the dust layer contribute increasingly more. Hänel et al. [61] generally observed an elevated aerosol layer at 2.5$5 \mathrm{~km}$ height caused by the complex mixture of aged desert dust, biomass burning smoke, and industrial pollution over eastern Asia at the Global Atmospheric Watch station of Shangdianzi near Beijing, China. In conclusion, the mixture of dust aerosol and locally emitted aerosols cause the large extinction and large AOD in Wuhan. 


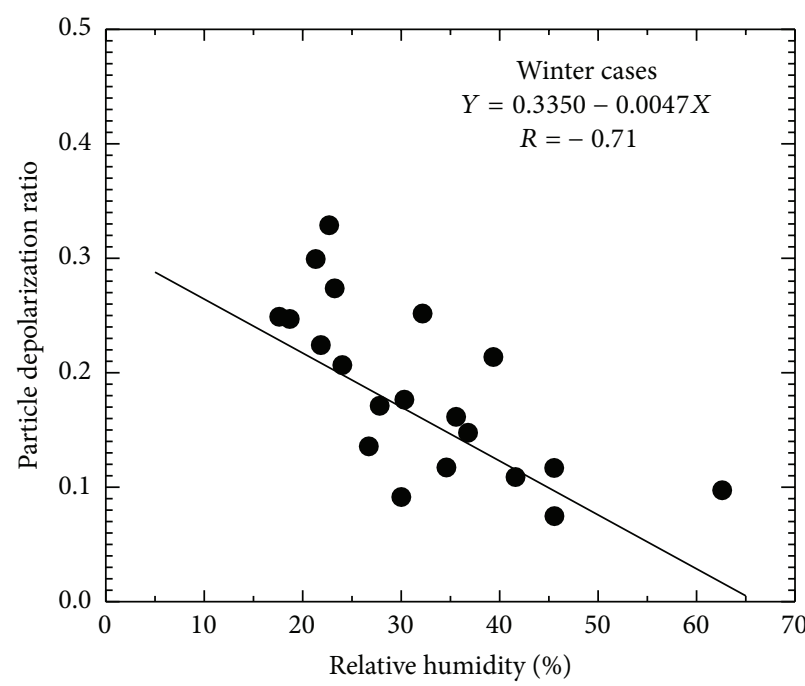

(a)

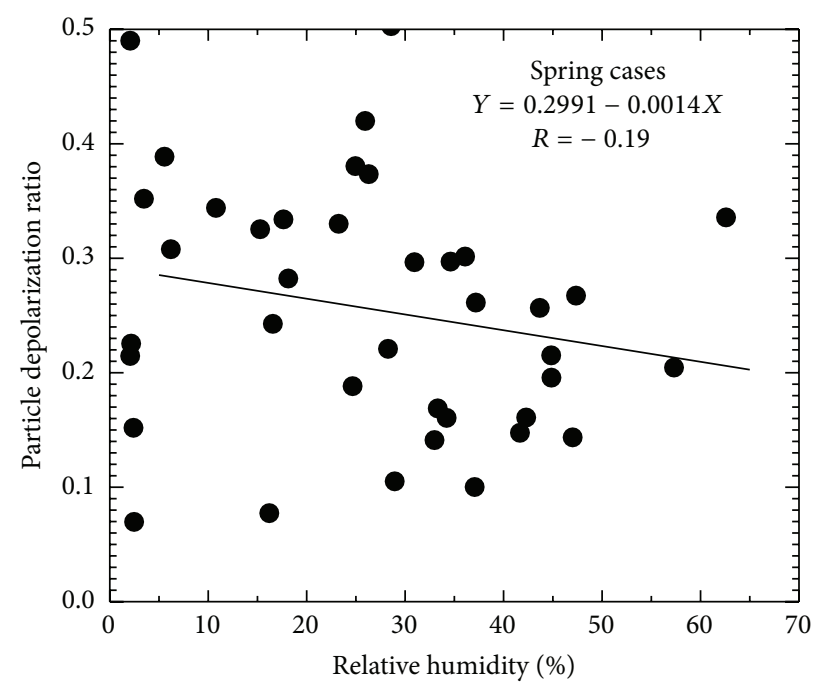

(b)

FIGURE 11: Scatter diagrams of the correlation between particle depolarization ratio and relative humidity measured during winter (a) and spring (b) dust events over Wuhan from October 2010 to September 2012. The relative humidity and particle depolarization ratio were simultaneously measured using the radiosondes and ground-based depolarization lidar. Here, $R$ represents the linear correlation coefficient.

\section{Summary and Conclusions}

In this study, two years of Asian dust transported over long distances were simultaneously observed using a groundbased depolarization lidar and CALIPSO at Wuhan $\left(30.5^{\circ} \mathrm{N}\right.$, $114.4^{\circ} \mathrm{E}$ ), China. The vertical distribution, horizontal range, and optical properties of the dust in 13 dust events were examined from October 2010 to September 2012. The results are summarized as follows.

The first case, which was a long-duration, intense dust event, occurred on 22-29 April 2011. The dust layer primarily occurred at a height of $1.52-5.02 \mathrm{~km}$ and had a mean centroid height of $3.04 \mathrm{~km}$. The mean volume depolarization ratio, particle depolarization ratio, extinction, and optical depth were $0.12,0.24,0.11 \mathrm{~km}^{-1}$, and 0.38 , respectively. The doublelayer structure observed using the depolarization lidar during the period 22-25 April was also seen in the CALIPSO data at heights of $1-4 \mathrm{~km}$ and $3-9 \mathrm{~km}$. The horizontal ranges of the dust layers were $\sim 950 \mathrm{~km}$ and $\sim 750 \mathrm{~km}$ on 23 April. The second case, which occurred on 7-9 December 2010, contained a single layer extending from the ground surface to a height of $2.22 \mathrm{~km}$ and had a mean centroid height of $1.02 \mathrm{~km}$. The mean volume depolarization ratio, particle depolarization ratio, extinction, and optical depth were 0.15 , $0.27,0.13 \mathrm{~km}^{-1}$, and 0.26 , respectively. The dust plume was observed at a height of $0-2 \mathrm{~km}$ and had a horizontal range of $\sim 1300 \mathrm{~km}$, based on the CALIPSO data.

The statistical characteristics of the dust were also examined. The dust primarily occurred at a height of approximately $1.45-3.51 \mathrm{~km}$ and had a mean centroid height of $2.34 \mathrm{~km}$. A mean $\delta$ of 0.12 , as well as the mean $\delta_{p}$ of 0.22 , was observed, indicating the mixing of other spherical aerosols and the hygroscopic growth of the dust particles. The extinction and AOD exhibited large variations; the mean extinction and
AOD were $0.19 \mathrm{~km}^{-1}$ and 0.32 , respectively. The CALIPSO data indicate that the dust plumes had horizontal ranges of approximately $750-2400 \mathrm{~km}$ in 9 cases.

The dust occurrence probability over Wuhan in the winter $(0.68)$ is slightly smaller than that in spring $(0.73)$. Moreover, there are a few dust features that differ between the spring and winter. The springtime dust layers tend to be higher due to more intense Asian dust outbreaks, which are caused by the higher frequency of strong winds. The mean extinction and $\mathrm{AOD}$ are $140 \%$ and $31 \%$ larger in the winter, respectively. Moreover, the $\delta$ and $\delta_{p}$ are $20 \%$ and $50 \%$ smaller in the winter, respectively. These differences may be due to the temperature inversion in the lower troposphere, the mixing of local aerosols, and hygroscopic growth under suitable $\mathrm{RH}$ conditions. Compared with other downstream dust regions, the dust aerosols over Wuhan exhibit a larger extinction and AOD and a smaller $\delta$.

Dust largely affects Wuhan during the spring and winter every year, and different spring and winter dust properties were observed in this study. However, the precise explanations for these different characteristics require more extensive study and further analysis. The optical properties of dust obtained only by polarization lidar are limited. The lidar ratio and Ångström exponent are two other important parameters to depict the microphysics properties of dust aerosols, which may help us to further understand the particle size and absorbing property. Therefore, multiwavelength Raman/polarization lidar observations are needed at out site. We will perform such studies in the future.

\section{Conflict of Interests}

The authors declare that there is no conflict of interests regarding the publication of this paper. 


\section{Acknowledgments}

This research is jointly supported by the National Natural Science Foundation of China through Grants 40221003 and 41327801 and the Ocean Public Welfare Scientific Research Project from State Oceanic Administration, People's Republic of China (no. 201005017). The authors appreciate the enlightening comments and valuable suggestions of the anonymous reviewers. The authors also thank Wei Kong and Yunpeng Zhang for their technical assistance and support in collecting the lidar data. The CALIPSO data were acquired from the Atmospheric Science Data Central at the NASA Langley Research Center.

\section{References}

[1] Y. J. Kaufman, D. Tanré, and O. Boucher, "A satellite view of aerosols in the climate system," Nature, vol. 419, no. 6903, pp. 215-223, 2002.

[2] J. Sun, M. Zhang, and T. Liu, "Spatial and temporal characteristics of dust storms in China and its surrounding regions, 1960-1999: Relations to source area and climate," Journal of Geophysical Research D: Atmospheres, vol. 106, no. 10, pp. 1032510333, 2001.

[3] J. M. Creamean, K. J. Suski, D. Rosenfeld et al., "Dust and biological aerosols from the Sahara and Asia influence precipitation in the Western U.S," Science, vol. 340, no. 6127, pp. 1572-1578, 2013.

[4] I. Tegen, A. A. Lacis, and I. Fung, "The influence on climate forcing of mineral aerosols from disturbed soils," Nature, vol. 380, no. 6573, pp. 419-422, 1996.

[5] S. A. Kwon, Y. Iwasaka, T. Shibata, and T. Sakai, "Vertical distribution of atmospheric particles and water vapor densities in the free troposphere: lidar measurement in spring and summer in Nagoya, Japan," Atmospheric Environment, vol. 31, no. 10, pp. 1459-1465, 1997.

[6] M. O. Andreae, "Climate effects of changing atmospheric aerosol levels," in Future Climates of the World: A Modelling Perspective, vol. 16 of World Survey of Climatology, pp. 341-392, Elsevier, New York, NY, USA, 1995.

[7] C. S. Zender, R. L. Miller, and I. Tegen, "Quantifying mineral dust mass budgets: terminology, constraints, and current estimates," Eos, vol. 85, no. 48, pp. 509-512, 2004.

[8] X. Y. Zhang, R. Arimoto, and Z. S. An, "Dust emission from Chinese desert sources linked to variations in atmospheric circulation," Journal of Geophysical Research D: Atmospheres, vol. 102, no. 23, pp. 28041-28047, 1997.

[9] S. C. Hsu, C. A. Huh, C. Y. Lin et al., "Dust transport from nonEast Asian sources to the North Pacific," Geophysical Research Letters, vol. 39, no. 12, Article ID L12804, 2012.

[10] I. Uno, K. Eguchi, K. Yumimoto et al., "Asian dust transported one full circuit around the globe," Nature Geoscience, vol. 2, no. 8, pp. 557-560, 2009.

[11] Z. Levin, A. Teller, E. Ganor, and Y. Yin, "On the interactions of mineral dust, sea-salt particles, and clouds: a measurement and modeling study from the Mediterranean Israeli Dust Experiment campaign," Journal of Geophysical Research D: Atmospheres, vol. 110, no. 20, Article ID D20202, pp. 1-19, 2005.

[12] I. N. Sokolik and O. B. Toon, "Direct radiative forcing by anthropogenic airborne mineral aerosols," Nature, vol. 381, no. 6584, pp. 681-683, 1996.
[13] K. Niranjan, B. L. Madhavan, and V. Sreekanth, "Micro pulse lidar observation of high altitude aerosol layers at Visakhapatnam located on the east coast of India," Geophysical Research Letters, vol. 34, no. 3, Article ID L03815, 2007.

[14] A. Papayannis, H. Q. Zhang, V. Amiridis et al., "Extraordinary dust event over Beijing, China, during April 2006: lidar, sun photometric, satellite observations and model validation," Geophysical Research Letters, vol. 34, no. 7, Article ID L07806, 2007.

[15] T. Sakai, T. Shibata, S.-A. Kwon, Y.-S. Kim, and Y. Iwasaka, "Free tropospheric aerosol backscatter, depolarization ratio, and relative humidity measured with the Raman lidar at Nagoya in 1994-1997: contributions of aerosols from the Asian Continent and the Pacific Ocean," Atmospheric Environment, vol. 34, no. 3, pp. 431-442, 2000.

[16] T. Sakai, T. Shibata, Y. Iwasaka et al., "Case study of Raman lidar measurements of Asian dust events in 2000 and 2001 at Nagoya and Tsukuba, Japan," Atmospheric Environment, vol. 36, no. 35, pp. 5479-5489, 2002.

[17] N. Sugimoto, I. Uno, M. Nishikawa et al., "Record heavy Asian dust in Beijing in 2002: observations and model analysis of recent events," Geophysical Research Letters, vol. 30, no. 12, 2003.

[18] S.-W. Kim, S.-C. Yoon, J. Kim, and S.-Y. Kim, "Seasonal and monthly variations of columnar aerosol optical properties over east Asia determined from multi-year MODIS, LIDAR, and AERONET Sun/sky radiometer measurements," Atmospheric Environment, vol. 41, no. 8, pp. 1634-1651, 2007.

[19] R. Gautam, Z. Liu, R. P. Singh, and N. C. Hsu, "Two contrasting dust-dominant periods over India observed from MODIS and CALIPSO data," Geophysical Research Letters, vol. 36, no. 6, Article ID L06813, 2009.

[20] J. Huang, P. Minnis, Y. Yi et al., "Summer dust aerosols detected from CALIPSO over the Tibetan Plateau," Geophysical Research Letters, vol. 34, no. 18, Article ID L18805, 2007.

[21] J. Huang, P. Minnis, B. Chen et al., "Long-range transport and vertical structure of Asian dust from CALIPSO and surface measurements during PACDEX," Journal of Geophysical Research D: Atmospheres, vol. 113, no. 23, Article ID D23212, 2008.

[22] S.-W. Kim, S.-C. Yoon, J. Kim, J.-Y. Kang, and N. Sugimoto, "Asian dust event observed in Seoul, Korea, during 29-31 May 2008: analysis of transport and vertical distribution of dust particles from lidar and surface measurements," Science of the Total Environment, vol. 408, no. 7, pp. 1707-1718, 2010.

[23] D. Liu, Z. Wang, Z. Liu, D. Winker, and C. Trepte, "A height resolved global view of dust aerosols from the first year CALIPSO lidar measurements," Journal of Geophysical Research D: Atmospheres, vol. 113, no. 16, Article ID D16214, 2008.

[24] D. Liu, Y. Wang, Z. Wang, and J. Zhou, "The three-dimensional structure of transatlantic african dust transport: a new perspective from CALIPSO LIDAR measurements," Advances in Meteorology, vol. 2012, Article ID 850704, 9 pages, 2012.

[25] J. B. Nee, C. W. Chiang, H. L. Hu, S. X. Hu, and J. Y. Yu, "Lidar measurements of Asian dust storms and dust cloud interactions," Journal of Geophysical Research: Atmospheres, vol. 112, no. 15, Article ID D15202, 2007.

[26] J. Zhou, G. Yu, C. Jin et al., "Lidar observations of Asian dust over Hefei, China in spring 2000," Journal of Geophysical Research D, vol. 107, no. 15, pp. 1-8, 2002.

[27] A. Behrendt and T. Nakamura, "Calculation of the calibration constant of polarization lidar and its dependency on atmospheric temperature," Optics Express, vol. 10, no. 16, pp. 805-817, 2002. 
[28] K. Sassen, "The polarization lidar technique for cloud research: a review and current assessment," Bulletin of the American Meteorological Society, vol. 72, no. 12, pp. 1848-1866, 1991.

[29] J. B. Nee, C. N. Len, W. N. Chen, and C. I. Lin, "Lidar observation of the cirrus cloud in the tropopause at Chung- $\mathrm{Li}\left(25^{\circ} \mathrm{N}\right.$, $\left.121^{\circ} \mathrm{E}\right)$," Journal of the Atmospheric Sciences, vol. 55, no. 12, pp. 2249-2257, 1998.

[30] Z. Liu, N. Sugimoto, and T. Murayama, "Extinction-tobackscatter ratio of Asian dust observed with high-spectralresolution lidar and Raman lidar," Applied Optics, vol. 41, no. 15, pp. 2760-2767, 2002.

[31] A. R. Sharma, S. K. Kharol, and K. V. S. Badarinath, "LIDAR observations of aerosol properties over tropical urban regiona case study during a low-pressure system over bay of bengal," IEEE Geoscience and Remote Sensing Letters, vol. 6, no. 4, pp. 807-811, 2009.

[32] F. G. Fernald, "Analysis of atmospheric lidar observations: some comments," Applied Optics, vol. 23, pp. 652-653, 1984.

[33] T. Takamura, Y. Sasano, and T. Hayasaka, "Tropospheric aerosol optical properties derived from lidar, sun photometer, and optical particle counter measurements," Applied Optics, vol. 33, no. 30, pp. 7132-7140, 1994.

[34] T. Murayama, M. Furushima, A. Oda et al., "Aerosol optical properties in the urban mixing layer studied by polarization lidar with meteorological data," in Advances in Atmospheric Remote Sensing with Lidar, A. Ansmann, R. Neuber, P. Rairoux, and U. Wandinger, Eds., pp. 19-22, Springer, New York, NY, USA, 1997.

[35] T. Murayama, H. Okamoto, N. Kaneyasu, H. Kamataki, and K. Miura, "Application of lidar depolarization measurement in the atmospheric boundary layer: effects of dust and sea-salt particles," Journal of Geophysical Research, vol. 104, no. 24, pp. 31781-31792, 1999.

[36] C. W. Chiang, W. N. Chen, W. A. Liang, S. K. Das, and J. B. Nee, "Optical properties of tropospheric aerosols based on measurements of lidar, sun-photometer, and visibility at Chung-Li $\left(25^{\circ} \mathrm{N}, 121^{\circ} \mathrm{E}\right)$," Atmospheric Environment, vol. 41, no. 19, pp. 4128-4137, 2007.

[37] Y. M. Noh, Y. J. Kim, and D. Müller, "Seasonal characteristics of lidar ratios measured with a Raman lidar at Gwangju, Korea in spring and autumn," Atmospheric Environment, vol. 42, no. 9, pp. 2208-2224, 2008.

[38] D. M. Winker, W. H. Hunt, and M. J. McGill, "Initial performance assessment of CALIOP," Geophysical Research Letters, vol. 34, no. 19, Article ID L19803, 2007.

[39] Z. Liu, A. Omar, M. Vaughan et al., "CALIPSO lidar observations of the optical properties of Saharan dust: a case study of long-range transport," Journal of Geophysical Research, vol. 113, no. D7, Article ID D07207, 2008.

[40] B. N. Holben, T. F. Eck, I. Slutsker et al., "AERONET-a federated instrument network and data archive for aerosol characterization," Remote Sensing of Environment, vol. 66, no. 1, pp. 1-16, 1998.

[41] M. D. King, D. M. Byrne, B. M. Herman, and J. A. Reagan, "Aerosol size distributions obtained by inversion of spectral optical depth measurements," Journal of the Atmospheric Sciences, vol. 35, no. 11, pp. 2153-2167, 1978.

[42] R. R. Draxler and G. D. Rolph, HYSPLIT (Hybrid SingleParticle Lagrangian Integrated Trajectory) Model, Air Resources Laboratory, NOAA, Silver Spring, Md, USA, 2003, http://www .arl.noaa.gov/ready/hysplit4.html.
[43] W. Gong, S. Zhang, and Y. Ma, "Aerosol optical properties and determination of aerosol size distribution in Wuhan, China," Atmosphere, vol. 5, no. 1, pp. 81-91, 2014.

[44] J. Liu, Y. Zheng, Z. Li, C. Flynn, E. J. Welton, and M. Cribb, "Transport, vertical structure and radiative properties of dust events in southeast China determined from ground and space sensors," Atmospheric Environment, vol. 45, no. 35, pp. 64696480, 2011.

[45] J. Liu, Y. Zheng, Z. Li, C. Flynn, and M. Cribb, "Seasonal variations of aerosol optical properties, vertical distribution and associated radiative effects in the Yangtze Delta region of China," Journal of Geophysical Research, vol. 117, no. D16, Article ID D00K38, 2012.

[46] Y. Zheng, J. Liu, R. Wu et al., "Seasonal statistical characteristics of aerosol optical properties at a site near a dust region in China," Journal of Geophysical Research, vol. 113, no. D16, Article ID D16205, 2008.

[47] Y. Kurosaki and M. Mikami, "Recent frequent dust events and their relation to surface wind in East Asia," Geophysical Research Letters, vol. 30, no. 14, p. 1736, 2003.

[48] Y. H. Zhang, S. D. Zhang, and F. Yi, "Intensive radiosonde observations of lower tropospheric inversion layers over Yichang, China," Journal of Atmospheric and Solar-Terrestrial Physics, vol. 71, no. 1, pp. 180-190, 2009.

[49] C. E. Jordan, J. E. Dibb, B. E. Anderson, and H. E. Fuelberg, "Uptake of nitrate and sulfate on dust aerosols during TRACEP," Journal of Geophysical Research D: Atmospheres, vol. 108, no. 21, pp. 1-38, 2003.

[50] T. Murayama, M. Furushima, A. Oda, N. Iwasaka, and K. Kai, "Depolarization ratio measurements in the atmospheric boundary layer by lidar in Tokyo," Journal of the Meteorological Society of Japan, vol. 74, no. 4, pp. 571-578, 1996.

[51] M. Ikegami, K. Okada, Y. Zaizen et al., "Aerosol particles in the middle troposphere over the northern Pacific," Journal of the Meteorological Society of Japan, vol. 71, pp. 517-528, 1993.

[52] B.-G. Kim and S.-U. Park, "Transport and evolution of a wintertime yellow sand observed in Korea," Atmospheric Environment, vol. 35, no. 18, pp. 3191-3201, 2001.

[53] S. W. Kim, S. C. Yoon, and J. Kim, "Columnar Asian dust particle properties observed by sun/sky radiometers from 2000 to 2006 in Korea," Atmospheric Environment, vol. 42, no. 3, pp. 492-504, 2008.

[54] J. Kim, "Transport routes and source regions of Asian dust observed in Korea during the past 40 years (1965-2004)," Atmospheric Environment, vol. 42, no. 19, pp. 4778-4789, 2008.

[55] C. B. Park, J. H. Kim, and C. H. Lee, "Measurement of Asian dust by using of multiwavelength lidar," in Lidar Remote Sensing for Industry and Environment Monitoring, vol. 4153 of Proceedings of the SPIE, pp. 124-131, Sendai, Japan, October 2000.

[56] N. Sugimoto, I. Matsui, Z. Liu, A. Shimizu, I. Tamamushi, and K. Asai, "Observation of aerosols and clouds using a twowavelength polarization Lidar during the Nauru99 experiment," Sea and Sky, vol. 76, pp. 93-98, 2000.

[57] P. Cottle, K. Strawbridge, I. Mckendry, N. O’Neill, and A. Saha, "A pervasive and persistent asian dust event over North America during spring 2010: lidar and sunphotometer observations," Atmospheric Chemistry and Physics, vol. 13, no. 9, pp. 4515-4527, 2013.

[58] A. Deleva and I. Grigorov, "Lower troposphere observation over urban area with lidar at 1064nm," International Journal of Navigation and Observation, vol. 2011, Article ID 769264, 8 pages, 2011. 
[59] D. S. Balis, V. Amiridis, S. Nickovic, A. Papayannis, and C. Zerefos, "Optical properties of Saharan dust layers as detected by a Raman lidar at Thessaloniki, Greece," Geophysical Research Letters, vol. 31, no. 13, 2004.

[60] A. Papayannis, V. Amiridis, L. Mona et al., "Systematic lidar observations of Saharan dust over Europe in the frame of EARLINET (2000-2002)," Journal of Geophysical Research D: Atmospheres, vol. 113, no. 10, Article ID D10204, 2008.

[61] A. Hänel, H. Baars, D. Althausen, A. Ansmann, R. Engelmann, and J. Y. Sun, "One-year aerosol profiling with EUCAARI Raman lidar at Shangdianzi GAW station: Beijing plume and seasonal variations," Journal of Geophysical Research D: Atmospheres, vol. 117, no. 13, Article ID D13201, 2012. 

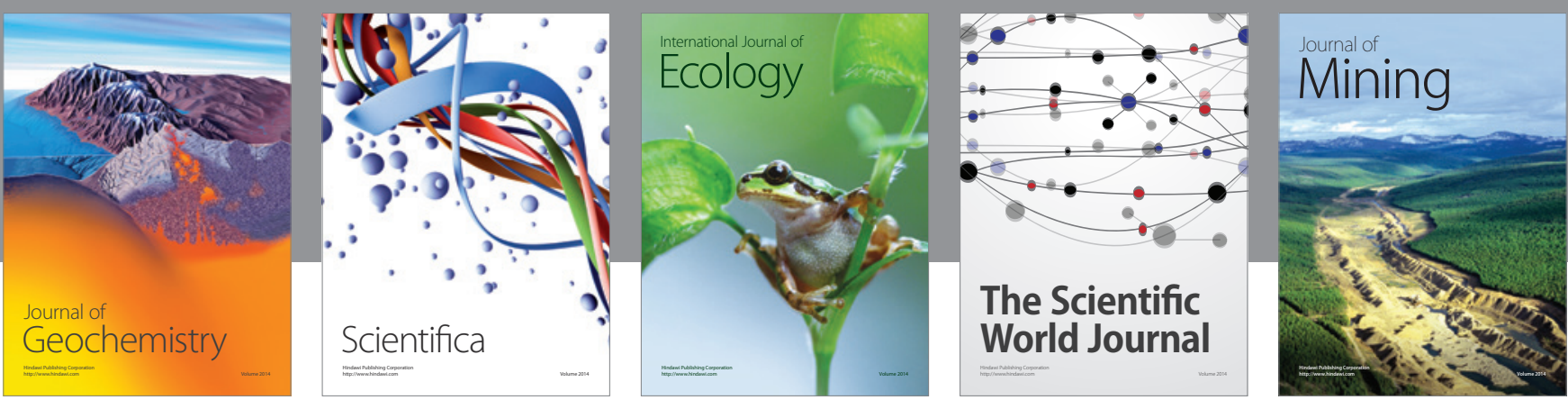

The Scientific World Journal
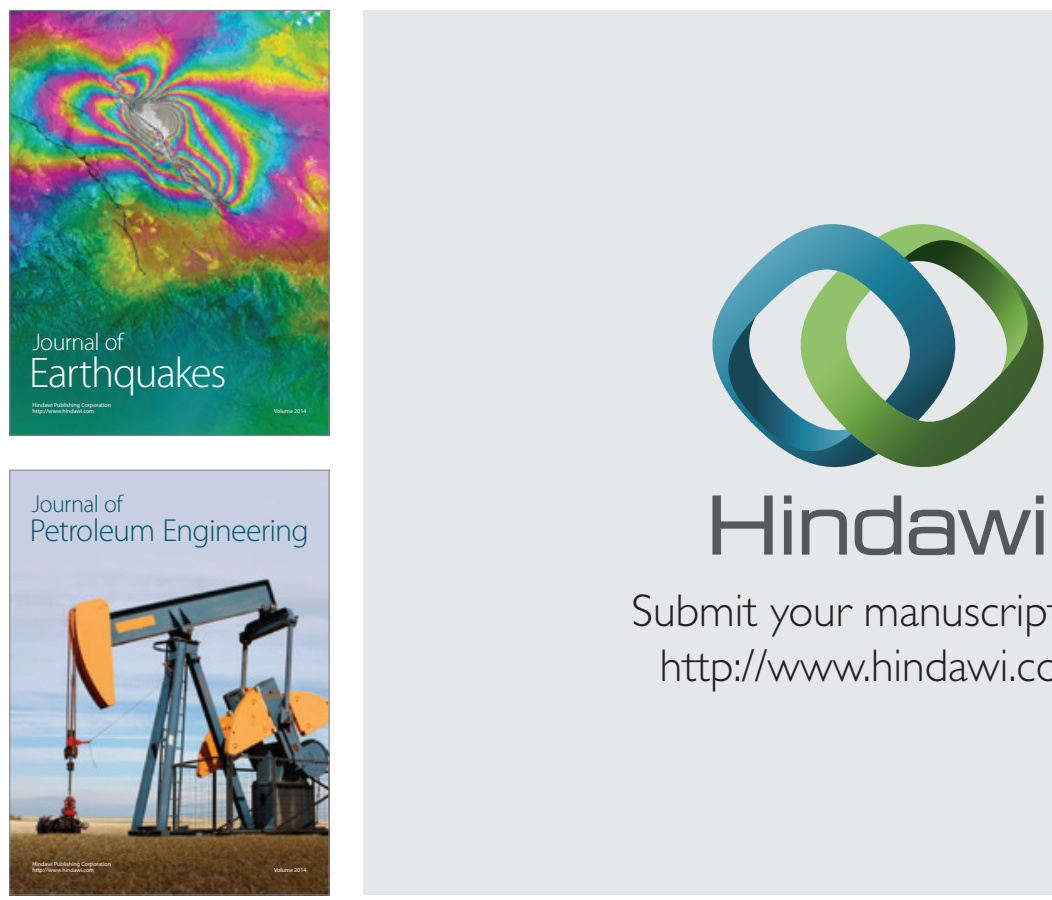

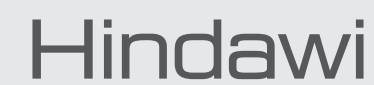

Submit your manuscripts at

http://www.hindawi.com
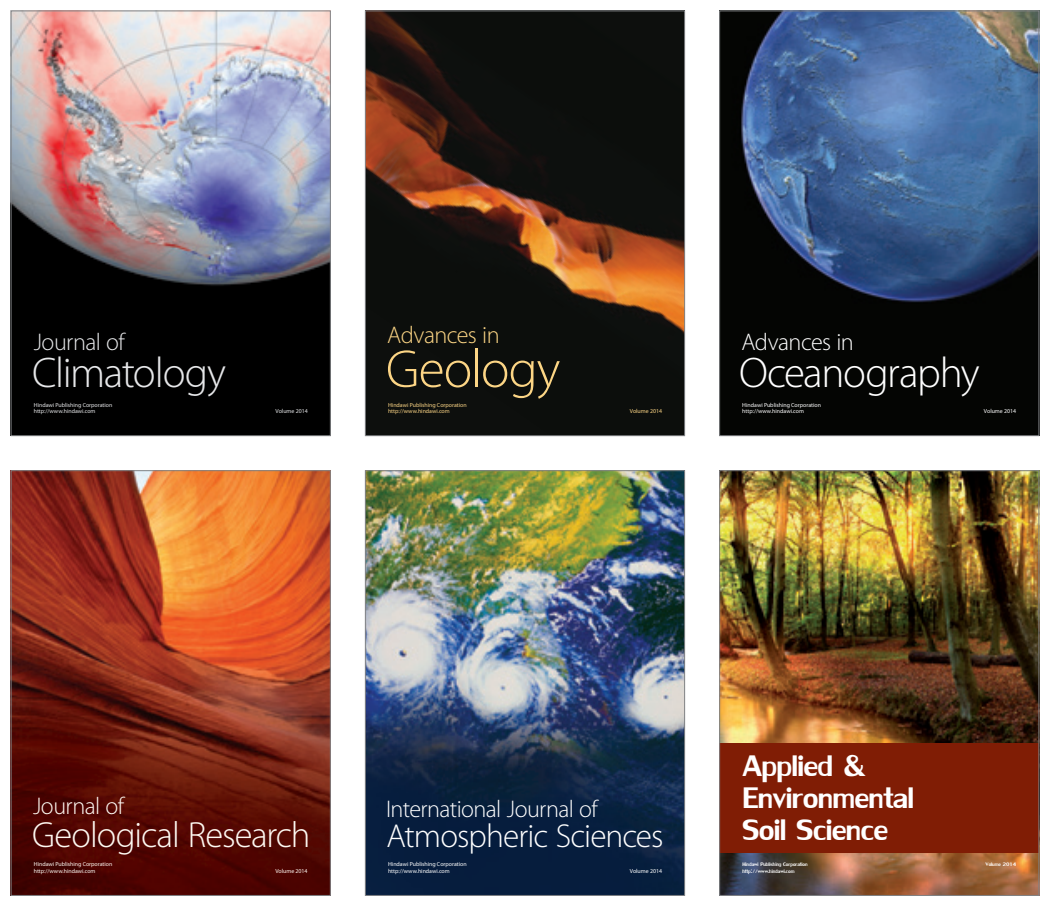
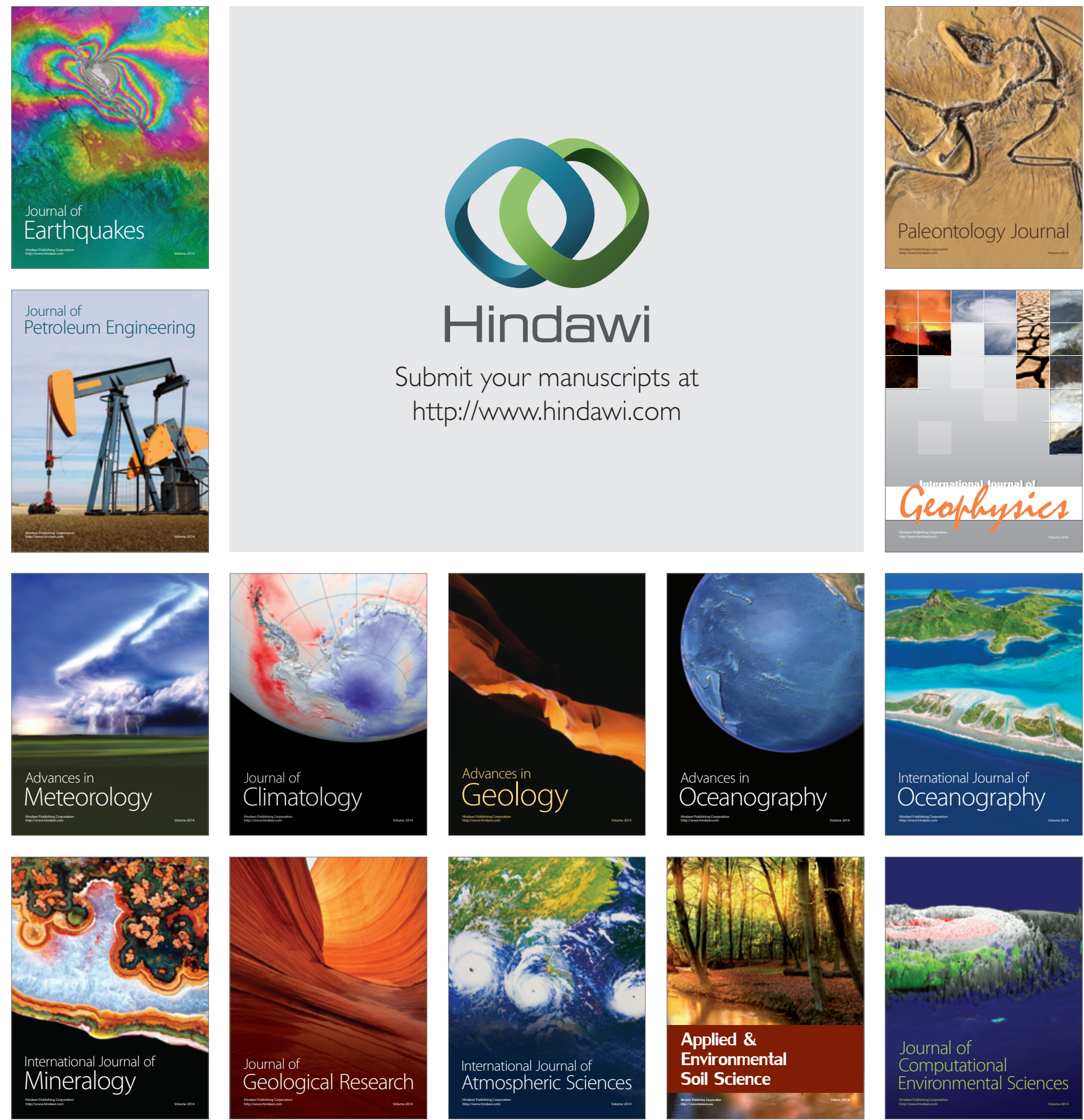